\title{
Neuroinflammation as an etiological trigger for depression comorbid with inflammatory bowel disease
}

\author{
Colin F. Craig ${ }^{1}$, Rhiannon T. Filippone ${ }^{1}$, Rhian Stavely ${ }^{1,2}$, Joel C. Bornstein ${ }^{3}$, Vasso Apostolopoulos ${ }^{1,4}$ and \\ Kulmira Nurgali ${ }^{1,5,6,7^{*}}$ (D)
}

\begin{abstract}
Patients with inflammatory bowel disease (IBD) suffer from depression at higher rates than the general population. An etiological trigger of depressive symptoms is theorised to be inflammation within the central nervous system. It is believed that heightened intestinal inflammation and dysfunction of the enteric nervous system (ENS) contribute to impaired intestinal permeability, which facilitates the translocation of intestinal enterotoxins into the blood circulation. Consequently, these may compromise the immunological and physiological functioning of distant non-intestinal tissues such as the brain. In vivo models of colitis provide evidence of increased blood-brain barrier permeability and enhanced central nervous system (CNS) immune activity triggered by intestinal enterotoxins and blood-borne inflammatory mediators. Understanding the immunological, physiological, and structural changes associated with IBD and neuroinflammation may aid in the development of more tailored and suitable pharmaceutical treatment for IBD-associated depression.
\end{abstract}

Keywords: Inflammatory bowel disease, Depression, Neuroinflammation, Gut-brain axis

\section{Introduction}

Inflammatory bowel disease (IBD) is believed to affect up to 7 million people globally with the incidence rising in many western countries [1]. Patients diagnosed with IBD have higher rates of depression and anxiety compared to the general population [2]. Depression is often associates with poorer compliance to treatment regimens and increases the risk of morbidity and mortality of individuals with a chronic medical condition [3, 4]. The gut-brain axis is believed to play a significant role in pathogeneses and/or relapse of IBD symptoms [5]. This review aims to reveal the pathophysiological alterations in the gut and brain in IBD patients and animal models of colitis.

\footnotetext{
*Correspondence: kulmira.nurgali@vu.edu.au

${ }^{7}$ Institute for Health and Sport, Victoria University, Level 4 Research Labs,

Western Centre for Health Research and Education, Sunshine Hospital,

176 Furlong Road, St Albans, VIC 3021, Australia

Full list of author information is available at the end of the article
}

It may provide an insight into neurobiological mechanisms, which could be targeted to relieve depression in IBD patients. Better-suited pharmacological approaches to IBD patients with depression will help to relieve the immense psychological burden of this debilitating chronic disease and potentially help to correct the gutbrain axis to prevent the recurrence of intestinal inflammation. Moreover, underlying mechanisms of depression comorbid with IBD may be highly translatable to other diseases such as rheumatoid arthritis, obstructive pulmonary disease, and diabetes, which demonstrate higher rates of depression compared to the general population $[6,7,8]$.

\section{Background}

Inflammatory bowel disease (IBD) is an idiopathic condition that manifests as chronic inflammation within the gastrointestinal (GI) tract and affects approximately

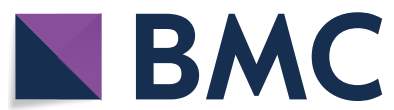

(c) The Author(s) 2021. Open Access This article is licensed under a Creative Commons Attribution 4.0 International License, which permits use, sharing, adaptation, distribution and reproduction in any medium or format, as long as you give appropriate credit to the original author(s) and the source, provide a link to the Creative Commons licence, and indicate if changes were made. The images or other third party material in this article are included in the article's Creative Commons licence, unless indicated otherwise in a credit line to the material. If material is not included in the article's Creative Commons licence and your intended use is not permitted by statutory regulation or exceeds the permitted use, you will need to obtain permission directly from the copyright holder. To view a copy of this licence, visit http://creativecommons.org/licenses/by/4.0/. The Creative Commons Public Domain Dedication waiver (http://creativeco mmons.org/publicdomain/zero/1.0/) applies to the data made available in this article, unless otherwise stated in a credit line to the data. 
7 million people worldwide [1]. The two major forms of IBD are ulcerative colitis (UC) and Crohn's disease (CD). UC is characterized by chronic inflammation leading to ulceration which affects primarily the colon and is restricted to the intestinal mucosa layer [9]. On the contrary, CD appears as transmural inflammatory lesions that present anywhere within the GI tract from the oropharynx to perianal areas [9]. Clinical symptoms including abdominal pain, hypersensitivity, diarrhea, blood and mucus in the stools, fatigue, and weight loss are similar between both pathologies of IBD [9]. Although the etiology of IBD remains largely obscure, it has been postulated that elements of an individual's genetics, environmental exposures, microbiota dysbiosis, and a dysregulated immune response may attribute to IBD pathogenesis $[9,10]$. It has been established that structural and functional abnormalities of the enteric nervous system (ENS), the intrinsic innervation of the GI tract, are associated with recurrence of symptoms and disease severity of IBD $[11,12]$. The combination of these factors induces abnormal innate and adaptive immunological responses that threaten the intestinal barrier integrity, cumulatively leading to systemic fallout and malfunctioning of the gut-brain axis [10]. Although IBD is an idiopathic disease affecting the GI tract, both human and animal studies have found a significant correlation between intestinal inflammation and psychological disorders [13]. Depression is as high as $21-27 \%$ in patients with IBD compared to $12-13 \%$ in healthy controls with the rate of depression rising to $35 \%$ during active IBD, with no notable differences between $\mathrm{CD}$ and $\mathrm{UC}$ pathologies $[14,15]$. A postulated aetiological trigger of depressive symptoms in IBD patients suggests systemic low-grade neuroinflammation [16]. It has been reported that neuroinflammation induces one or more of the following: (1) dysregulation of the hypothalamus-pituitary-adrenal (HPA) axis [17], (2) depletion of serotonin levels [18], and (3) alteration of neurogenesis in the hippocampus [19], all of which involved in major depressive disorder (MDD) [16]. Moreover, neuroinflammation-associated depressive symptoms may involve systemic immune factors as an etiological trigger. This has been supported by (i) high levels of pro-inflammatory cytokines in the circulation are seen in patients with MDD [20], (ii) disease treatments requiring exogenous administration of cytokines evoke psychiatric changes [21], (iii) in animals and humans, administration of lipopolysaccharide (LPS) accompanied by the release of pro-inflammatory cytokines provokes depressive symptoms referred to as sickness syndrome [22], (iv) peripheral inflammatory diseases such as rheumatoid arthritis, obstructive pulmonary disease type 1 and diabetes are often comorbid with depression [6-8]. It has been postulated that neuroinflammation-induced depression in IBD involves peripheral inflammatory mediators originating from the inflamed gut penetrating the $\mathrm{BBB}$ and either directly or indirectly activating the resident macrophage-like microglial cells within the central nervous system (CNS) [16, 23,24,25]. Activated microglial cells can produce enzymes and mediators that deplete serotonin availability, impair maturation and proliferation of hippocampal progenitor cells and promote neurodegeneration [26, 27].

This review explores in detail the structural and physiological alterations in the GI tract, blood circulation and CNS in IBD patients and corresponding animal models of IBD. The aim is to provide a link between the gut and the brain with a special focus on circulating immune factors and expose neurobiological and/or immunological overlap between MDD and IBD to elucidate an etiological framework for IBD comorbid with depression.

\section{Intestinal barrier dysfunction in IBD}

Structural changes to intercellular and intracellular proteins of the intestinal epithelium and significant alterations of intestinal mucous production imply dysfunctional intestinal barrier integrity in IBD patients enabling luminal antigens to penetrate and initiate local immune responses within the lamina propria $[28,29]$.

\section{The intestinal mucosa and epithelium}

The intestinal barrier includes a thick secreted hydrated mucus layer which provides a physical and chemical barrier against luminal microbiota and antigens, as well as lubricating the epithelium [28]. The epithelial barrier is composed of several different classes of intestinal epithelial cells involved in regulating and maintaining barrier functions [28]. These cells include the goblet and Paneth cells, which synthesize and produce the mucin glycoproteins and some anti-microbial proteins, whose synthesis in Goblet cells is under control of ENS produced IL-18 [28, 30]. Mucin proteins such as MUC2 provide the mucus layer with viscous properties [31] and enable the mucus to retain antimicrobial proteins such as defensins, cathelicidins, lysosomes, and immunoglobulins (Ig) such as soluble IgA, IgG, and IgM [28]. Patients with CD show goblet cell hypertrophy as expected with increased mucus formation and a moderate increase in expression of MUC2 and MUC3, and high expression of MUC4 [32]. UC patients exhibit a reduction in the number of goblet cells, MUC2, MUC3, and MUC4 resulting in a diminished mucosal barrier [32] (Fig. 1).

Although a dysfunctional mucus layer is observed in patients with IBD, in vivo animal models of colitis have revealed conflicting results. The Math 1 gene, also known as the Atonal homologue 1, is a transcription factor involved in the differentiation of goblet cells and Paneth 


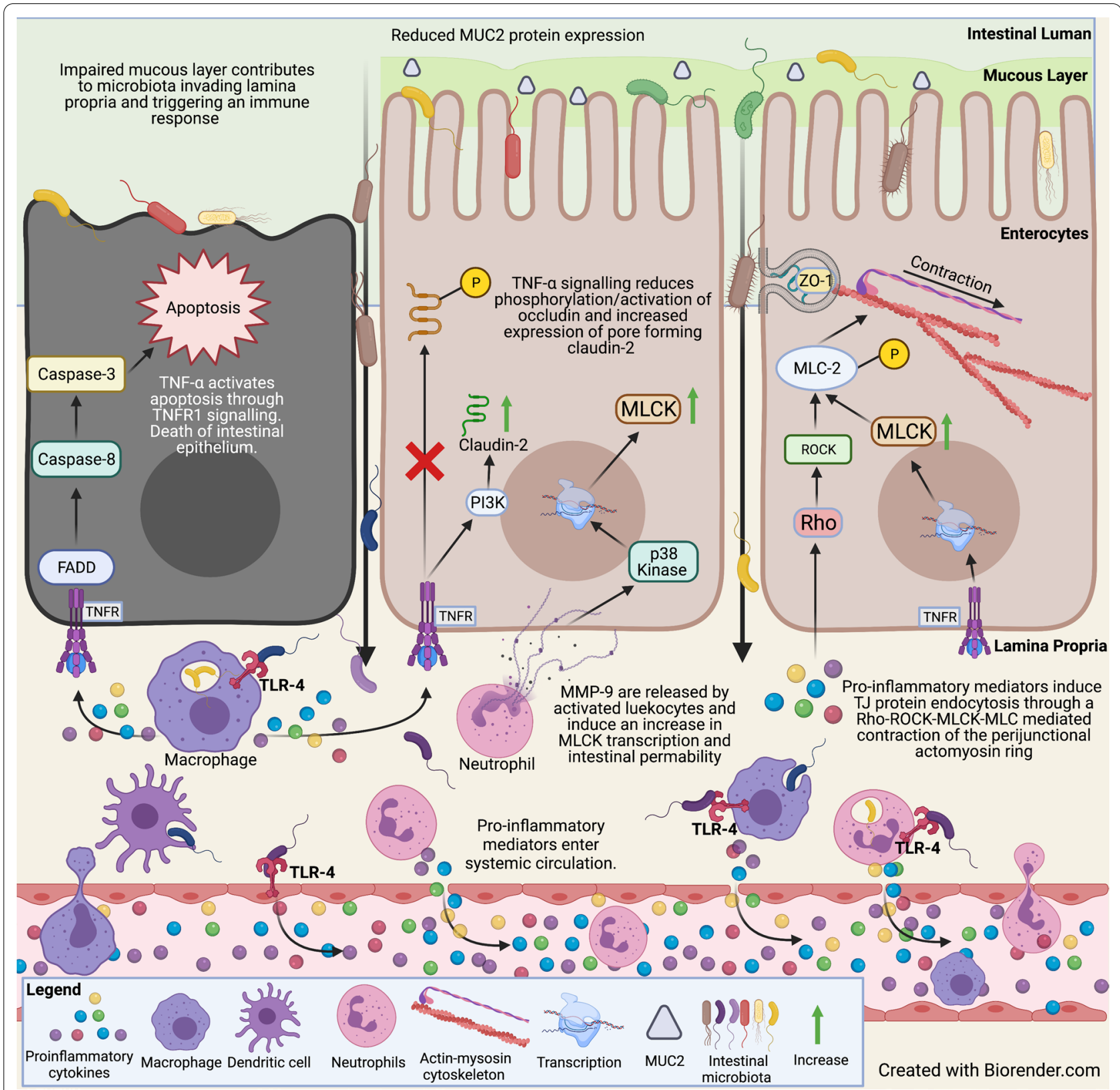

Fig. 1 Schematic overview of the mechanisms underlying intestinal barrier dysfunction commonly seen in human IBD and animal models of colitis. Impaired mucous production and composition and/or impaired tight junction protein localisation and production result in luminal microbiota and toxin paracellularly translocating into the intestinal lamina propria layer. Immune cells in this region interacting with antigens trigger the production of inflammatory mediators, which facilitate the recruitment of other leukocytes and lymphocytes. Inflammatory mediators enter peripheral circulation whereby they may trigger distant immunological activation. FADD Fas-associated protein with death domain; IFN Interferon; IL Interleukin; MLC myosin light chain; MLCK myosin light-chain kinase; MMP metalloproteinase, P phosphate; Pl3K phosphoinositide 3-kinase; ROCK Rho associated protein kinase; TJ tight junction; TLR toll-like receptor; TNF tumour necrosis factor; ZO zonula occludens

cells [33]. Use of an in vivo murine model of intestinal Math1 knockout demonstrated that $75-90 \%$ loss of secretory cells in the crypts and villi did not generate spontaneous colitis [34]. Moreover, transgenic mice possessing the toxic diphtheria gene, driven by the murine intestinal trefoil factor promoter that facilitated targeted ablation of goblet cells, had a decreased body weight loss and mortality rate (5\% vs $55 \%$ ) compared to non-transgenic mice following administration of dextran sulfate sodium (DSS) [35]. These findings suggest increased 
resistance to chemical administration of DSS following goblet cell reduction. These studies contrast with findings in the Winnie mouse model of spontaneous chronic colitis, which possesses a missense mutation on the $M u c 2$ gene resulting in robust intestinal inflammation with a phenotype and characteristics similar to UC patients [36, 37]. Histological and immunological presentation include increased intestinal production of pro-inflammatory cytokines, epithelial dysfunction, and endoplasmic reticulum stress within goblet and Paneth cells likely via aberrant folding and assembly of the mucin complex [36, 37]. These paradoxical in vivo findings require further investigation and suggest that a combination of normal mucous secretion and protein composition is a key to facilitating healthy physiological function. Overall, perturbations in mucous production are involved in robust inflammatory responses, which can eventuate in intestinal epithelial barrier dysfunction and may lead to invasion of intestinal contents and/or inflammatory mediators into blood circulation.

\section{The intestinal tight junctions}

The single-cell layer of the epithelium relies on paracellular protein junctional complexes such as tight junctions (TJs), adherens junctions, and desmosomes for structural integrity and cohesion [38]. TJs are on the apical side of the epithelial cells and provide a boundary between the basolateral and apical membranes [38]. TJs consist of transmembrane proteins such as claudin, occludin, junctional adhesion molecule (JAM), and tricellulin which interacts with peripheral membrane linker proteins such as zonula occludens ( $\mathrm{ZO}$ ) and cingulin which bind to cytoskeleton proteins including $\mathrm{F}$-actin and myosin [38]. The TJ protein complex acts like a "gate" which restricts paracellular entry of large hydrophilic molecules [38]. Altered TJ patterns have been observed in both IBD patients and animal models of intestinal inflammation with their dysfunctions enabling entry of luminal antigens into the lamina propria triggering inflammation [38]. Claudin proteins consist of 27 isoforms, which can be subdivided based on their functional roles [39]. Claudin-2 has been described to increase paracellular permeability, whereas claudin- $1,-3,-4,-5$, and -8 provide barrier strengthening properties for the cells of the epithelium $[39,40]$ (Table 1). The different claudin isoforms have been found to be both up and downregulated in the inflamed intestine from patients with $\operatorname{IBD}[39,40]$ (Table 1). Dampened expression for claudin-3, -4 , and -7 and increased expression of claudin- 1 and 2 are observed in the intestinal epithelium of UC patients $[40,41,42,43]$ (Table 1). Similarly, patients with $C D$ have reduced expression of claudin- $3,-4,-5$, and -8 proteins with an increased claudin- 1 and -2 intestinal epithelial expression $[40,44]$ (Table 1).

Table 1 A comparison of tight junction expression in patients with CD and UC and experimental models of colitis

\begin{tabular}{|c|c|c|c|c|c|}
\hline \multirow[t]{2}{*}{ Junction complex protein } & \multirow[t]{2}{*}{ Function } & \multicolumn{2}{|l|}{ Human IBD } & \multicolumn{2}{|c|}{$\begin{array}{l}\text { Mouse models of } \\
\text { colitis }\end{array}$} \\
\hline & & $C D$ & UC & TNBS & DSS \\
\hline Claudin-1 & Decreases paracellular permeability [39] & $\begin{array}{l}\uparrow \\
{[45]}\end{array}$ & $\begin{array}{l}\uparrow \\
{[43]}\end{array}$ & $\begin{array}{l}\downarrow \\
{[46]} \\
{[47]}\end{array}$ & $\begin{array}{l}\uparrow \\
{[48]}\end{array}$ \\
\hline Claudin-2 & Increases paracellular permeability. Important pore forming protein [39] & $\begin{array}{l}\uparrow \\
{[42,43]}\end{array}$ & $\begin{array}{l}\uparrow \\
{[42,43]}\end{array}$ & $\begin{array}{l}\downarrow \\
{[49]}\end{array}$ & $\begin{array}{l}\uparrow \\
{[50]}\end{array}$ \\
\hline Claudin -3 & Decreases paracellular permeability [40] & $\begin{array}{l}\downarrow \\
{[42]}\end{array}$ & $\begin{array}{l}\downarrow \\
{[42]}\end{array}$ & $\begin{array}{l}\downarrow \\
{[47]}\end{array}$ & \\
\hline Claudin-4 & Decreases paracellular permeability [39] & $\begin{array}{l}\downarrow \\
{[42]}\end{array}$ & $\begin{array}{l}\downarrow \\
{[42]}\end{array}$ & - & \\
\hline Claudin-5 & Decreases paracellular permeability [39] & $\begin{array}{l}\downarrow \\
{[44]}\end{array}$ & - & $\begin{array}{l}\text { No change } \\
{[47]}\end{array}$ & \\
\hline Claudin-7 & Acts as an anion barrier and pore [40] & $\begin{array}{l}\text { No change } \\
{[44]}\end{array}$ & $\downarrow$ & - & \\
\hline Claudin-8 & Decreases permeability [39] & $\begin{array}{l}\downarrow \\
{[44]}\end{array}$ & - & $\begin{array}{l}\downarrow \\
{[47]}\end{array}$ & \\
\hline Occludin & Regulates paracellular permeability and cellular adhesion [39] & $\begin{array}{l}\downarrow \\
{[52]}\end{array}$ & $\begin{array}{l}\downarrow \\
{[52]}\end{array}$ & $\begin{array}{l}\downarrow \\
{[47]}\end{array}$ & $\begin{array}{l}\downarrow \\
\text { [53] }\end{array}$ \\
\hline ZO-1 & Facilitates connection between TJ and intracellular actin cytoskeleton [39] & $\begin{array}{l}\downarrow \\
{[54]}\end{array}$ & $\begin{array}{l}\downarrow \\
{[55]}\end{array}$ & $\begin{array}{l}\downarrow \\
{[47]}\end{array}$ & $\begin{array}{l}\downarrow \\
{[46]}\end{array}$ \\
\hline MLCK & Phosphorylates MLC causing contraction of peri junctional actomyosin [56] & $\begin{array}{l}\uparrow \\
{[57]}\end{array}$ & $\begin{array}{l}\uparrow \\
{[57]}\end{array}$ & $\begin{array}{l}\uparrow \\
{[58]}\end{array}$ & $\begin{array}{l}\uparrow \\
{[59]}\end{array}$ \\
\hline Phosphorated (active) MLC & MLC facilitates internalisation of TJ [56] & $\begin{array}{l}\uparrow \\
{[57]}\end{array}$ & $\begin{array}{l}\uparrow \\
{[57]}\end{array}$ & $\begin{array}{l}\uparrow \\
{[60]}\end{array}$ & $\begin{array}{l}\uparrow \\
(59)\end{array}$ \\
\hline
\end{tabular}

$\uparrow$ upregulated; $\downarrow$ downregulated; - no explicit data; JAM junctional adhesion molecule; MLC myosin II regulatory light chain; MLCK myosin light chain kinase 
Other TJ proteins like occludins, JAM, and ZO have altered expression patterns in the inflamed intestinal mucosa from IBD patients. Occludin consists of four transmembrane domains and two extracellular loops [38]. Its phosphorylation state on serine and threonine residues determines its cellular localisation and hence TJ stability and permeability. A high phosphorylation state localises occludin in the membrane, whereas decreased phosphorylation correlates with cytoplasmic localisation [38]. Moreover, the occludin promoter can be downregulated by pro-inflammatory cytokines such as tumour necrosis factor (TNF)- $\alpha$ and interferon (IFN) $-\gamma$ [61]. IBD patients show decreased occludin protein and mRNA expression in the colonic mucosa, which may reflect occludin modulation via inhibition of its promoter [52, 61]. Treatment of the intestinal epithelial model of colorectal adenocarcinoma cells-2 (Caco-2) with TNF- $\alpha$ diminished expression of activated phosphorylated occludin which resulted in increased transepithelial permeability [62] (Fig. 1). The transmembrane TJ protein JAM has also been implicated in TJ dysfunction observed in colitis [63]. Reduced JAM-A protein expression at the level of the intestinal epithelium corresponding with enhanced intestinal permeability was observed in IBD patients [63]. Additionally, mice subjected to DSS-induced colitis in vivo following JAM-A deletion had an increased incidence of severe colitis and showed enhanced intestinal permeability [63]. It has been established that in vitro co-stimulation of epithelial cells with INF- $\gamma$ can induce the internalization of JAM-A [64].

Additionally, TNF- $\alpha$ treatment of Caco- 2 cells has profound effects on the linker protein $\mathrm{ZO}$ [65]. TNF- $\alpha$ induced downregulation and altered localization of $\mathrm{ZO}-1$ protein, accompanied by an increase in epithelial permeability in vitro [65]. It was found that IFN- $\gamma$ affects ZO-1 and occludin protein expression via the adenosine monophosphate-activated protein kinase-dependent pathway [54]. ZO proteins anchored to the cytoskeleton actomyosin ring can facilitate $\mathrm{TJ}$ contractions and endocytosis resulting in increased intestinal permeability [56]. Myosin light chain kinase (MLCK) and Rho-associated coiled containing protein kinase (ROCK) phosphorylate myosin light chain (MLC) causing contraction of perijunctional actomyosin rings [56] (Fig. 1). Increased activation of RhoA/ROCK has been detected in inflamed colonic mucosa from patients with $\mathrm{CD}$ and the rat model of trinitrobenzene sulfonic acid (TNBS)-induced colitis [66]. Intestinal tissue samples from patients with IBD have increased ileal epithelial MLCK and increased colonic expression of phosphorylated MLC-2 [56, 57]. These findings in IBD patients may be due to increased local production of TNF- $\alpha$ which increases MLCK1 synthesis [67]. Moreover, numerous pro-inflammatory cytokines implicated in IBD such as IFN- $\gamma$, TNF- $\alpha$, and interleukin (IL)-1 $\beta$ can induce TJ protein endocytosis through a Rho-ROCK-MLCK-MLC mediated contraction of the peri-junctional actomyosin ring $[68,69,70]$ (Fig. 1). Matrix metalloproteinases (MMPs)-9 synthesis and secretion are significantly induced after exposure to the cytokines (TNF-alpha, IL-1 alpha) and MMP-9 has been implicated in TJ epithelial dysfunction via a p38 kinase signal transduction pathway [71,72,73] (Fig. 1).

\section{ENS and intestinal permeability}

The ENS is believed to play a role in modulating intestinal permeability through the release of neurotransmitters and via the secretion of peptides and lipids by enteric glial cells (EGC) [74, 75]. The ENS is the largest division of the autonomic nervous system (ANS) and consists of a mesh-like system of neurons that influences GI functions such as segmentation, peristalsis, and secretion [74]. Importantly, the ENS is capable of acting independently of the sympathetic and parasympathetic nervous systems but can be modulated by them under certain circumstances [74]. The ENS can be subdivided into two major nerve plexi: the myenteric plexus, which functions to provide motor innervation to the longitudinal and circular muscles and to coordinate motility and secretion, and the submucosal plexus, which regulates secretion, vasodilation and probably has a role in immune responses [75].

Abnormalities of the ENS such as axonal damage and necrosis, neuronal death, and hyperplasia of EGCs are seen in IBD [76]. This affects normal gut functioning controlled by the ENS, which includes maintenance of the intestinal barrier.

Acetylcholine, endocannabinoids, neuropeptide $\mathrm{Y}$ (NPY), and VIP released by enteric neurons have been shown to alter intestinal permeability [77,78,79]. NPY is implicated in upregulation of the pore-forming claudin-2, which can increase intestinal permeability [80]. This is believed to be facilitated through a phosphatidyl inositol-3-kinase (PI3K) pathway and influenced by TNF given that TNF inhibitors reduce expression of NPY [80]. It is speculated that NPY and TNF may operate bidirectionally as in vivo studies in mice with complete knockout of NPY showed reduced secretion of TNF by enteric neurons accompanied by reduced intestinal permeability [80].

Cholinergic pathways are also implicated in intestinal permeability. The cholinergic agonist, nicotine, prevented an increased Caco- 2 permeability produced by exposure to cytomix which consists of cytokines known to increase intestinal permeability including TNF- $\alpha$, INF$\gamma$, and IL-1 $\beta$ [81]. Nicotine-induced barrier preservation is believed to be due to nicotine-activated EGCs, which 
prevents increased phosphorylation of ІкB $\alpha$ and NF- $\mathrm{KB}$ expression [81]. Primary cultures of porcine colonocytes exposed to the cholinergic agonist, carbachol, and the muscarinic agonist, oxotremorine, demonstrated enhanced transepithelial electrical resistance indicative of increased epithelial tightness [82].

Vasoactive intestinal polypeptide (VIP) may play a role in decreasing intestinal permeability following electrical field stimulation of submucosal neurons in vitro [79]. These findings were accompanied by enhanced expression of ZO-1 [79]. Impaired VIP signalling was observed in (TNBS)-induced colitis which is associated with a dramatic reduction of slow excitatory synaptic transmission in VIP-expressing secretomotor neurons in the submucosal plexus of guinea-pig [83]. Moreover, using sterically stabilized micelles for VIP administration (VIP-SSM), it was observed that a single dose of VIP-SSM significantly improved histological score, alleviated diarrhoea, and decreased pro-inflammatory cytokines in mice with DSSinduced colitis [84]. It could be theorised that reduced VIP levels may be in part responsible for impaired intestinal barrier noted in IBD patients, so VIP may be a useful therapeutic target in the future.

Cannabinoid signalling is an important mechanism of synaptic modulation in the nervous system and is believed to play a role in the intestinal barrier. Exogenous cannabinoids and endocannabinoids act on the G-protein coupled cannabinoid receptor (CBR) 1, which predominantly exists on nerve terminals where they may modulate neurotransmitter release, and on CBR2, which are found mainly on immune cells where they can mediate immune suppression [85]. CBR1 has been localized on myenteric neurons of the rat and guinea-pig intestine where nearly all cholinergic neurons express CBR1 and has been shown to preserve intestinal barrier integrity [86]. $\mathrm{CBR} 1^{-1-}$ mice exposed to stressful stimuli had enhanced expression of pro-inflammatory enzymes including cyclooxygenase-2 (COX2) and NOS2, increased colonic permeability to chromium-51-labelled ethylenediaminetetraacetic acid, and enhanced translocation of bacteria to the mesenteric lymph nodes compared to stressed wild type mice [78]. Degradation of barrier function was postulated to be due to NO-induced cytoskeleton rearrangement and subsequent tight junction dysfunction since in vitro and in vivo findings of NOS2 activity promoted intestinal epithelial permeability through NO synthesis [78, 87, 88].

The enteric glial population has a vital role in maintaining mucosal barrier function. Transgenic mice with targeted ablation of EGCs have a disrupted mucosal barrier and resultant inflammation with enhanced mucosal paracellular permeability to small fluorescent probes [89]. Moreover, Caco-2 cells co-cultured with enteric glia showed significantly greater transepithelial resistances and diminished permeability to fluorescein isothiocyanate (FITC)-dextran and fluorescein sulfonic acid. This correlated with a significant up-regulation of ZO-1 and occludin as increased $\mathrm{F}$-actin accumulation to lateral membranes [89]. These findings may be explained by EGC-derived neurotrophic factors, such as glial-derived S-nitrosoglutathione (GSNO) and glial cell line-derived neurotrophic factor (GDNF), which have been implicated in altering intestinal permeability $[89,90,91,92]$. GSNO administration in vitro and in vivo restored the appropriate localization and expression of ZO-1 and occludin, F-actin accumulation to the lateral membranes, as well as reduced phosphorylation of MLC in the intestinal epithelium [89, 91, 92]. Moreover, GSNO attenuated enhanced intestinal permeability induced by cytomix and LPS in Caco-2 cell cultures and rats, respectively [91, 92]. GSNO may influence tight junctions through S-nitrosylation of inhibitory $к B$ kinase (IKK), which prevents phosphorylation of the inhibitor of $\kappa \mathrm{B}$ (ІкB) [91, 92]. Interestingly, higher concentrations of GSNO have been shown to impair epithelial barrier function in vitro characterised by a marked disruption of the F-actin network [89]. Biopsy samples from CD patients, which trend toward higher mucosal permeability compared to controls, showed a significant reduction in permeability to FITC-inulin following the addition of GSNO [89]. This may suggest that the EGC network may be disrupted in intestinal mucosa of CD patients, resulting in lower tissue GSNO concentration. Lower concentrations of GSNO may impair tight junction expression and enhance intestinal permeability through an NFkB pathway [91, 92]. EGCs have been shown to be the main source of GDNF, which affects gut barrier properties [93]. GDNF administration to immature intestinal cell lines promoted linearized and augmented staining patterns of the tight junction proteins occludin and claudin-1, 5 at the cell borders as well as enhanced epithelial proliferation and decreased permeability assessed by FITC-dextran and transepithelial electrical resistance (TEER) [90]. Administration of GDNF in vitro or co-culture with EGCs reduced downregulation of tight junctions in rat intestinal epithelial cells and prevented the drop in TEER following ischemia-reperfusion injury [94]. Moreover, EGCs significantly increase GDNF expression when stimulated by hypoxia-reoxygenation [94]. Furthermore, GDNF has a potent anti-apoptotic effect on colonic epithelial cells via activation of both mitogen-activated protein kinase (MAPK) and PI3K/ AKt signalling pathways [95, 96]. Expression of GDNF and glial marker glial fibrillary acidic protein (GFAP) is significantly higher in inflamed colonic biopsies from UC patients than in healthy controls [97]. This may be due to enhanced pro-inflammatory cytokines being effective 
stimuli for GDNF secretion [93]. In contrast, reduced GFAP and GDNF expression is noted in CD patients [97]. In rats with DSS-induced colitis, recombinant adenoviral vectors encoding GDNF administered via the rectum significantly ameliorated the severity of inflammation [95].

Thus, the ENS plays a vital role in the maintenance of the intestinal barrier keeping the sterile lamina propria free of immunoreactive luminal antigens. During intestinal inflammation, the ENS may become damaged and lose its capacity to maintain the intestinal epithelial barrier contributing to impaired tight junction regulation, mucosal cell regeneration, and the invasion of luminal microbiota into the immune-rich lamina propria. Consequently, this helps facilitate entry of systemic inflammatory mediators into circulation, which may influence CNS neurobiology and mood states.

\section{Intestinal endothelial dysfunction}

The consequence of impaired epithelial integrity, mucus production and ENS dysfunction, is a translocation of luminal exogenous factors such as microbiota, toxins, and antigens into the lamina propria [98]. As a result, a robust inflammatory response facilitates the uptake of inflammatory mediators into peripheral circulation [99]. Following penetrations into lamina propria, luminal antigens are recognised by pattern recognition receptors such as toll-like receptors (TLR), nucleotide-binding and oligomerization domain, and C-type lectin receptors triggering the activation of a nuclear transcription factor NF- $\kappa$ B and inflammasomes [100]. This elicits the production of pro-inflammatory cytokines in the local tissue, including IL-1 $\beta$, IL-6, TNF $\alpha$, IFN- $\gamma$, and cytokines involved in the IL-23/Th17 pathway [100, 101]. Inflammation leads to endothelial cell dysfunction and therefore may facilitate translation of pro-inflammatory mediators from gut to the peripheral circulation [102, 103]. Human intestinal microvascular endothelial cell cultures can produce different cytokines (IL-1 $\beta$, IL-3, and IL-6) on stimulation with pro-inflammatory cytokines such as TNF- $\alpha$ and IL-1 [103]. Additionally, gut endothelial cells constitutively express TLR5 on their basolateral surface [104]. The binding of flagellin, a prominent antigen in IBD, can induce these endothelial cells to produce pro-inflammatory cytokines and adhesion molecules [103, 105] (Fig. 1).

Many anti-inflammatory cytokines have been implicated in the pathogenesis of IBD and have varying implications in endothelial functions, including transforming growth factor beta (TGF- $\beta$ ) and IL-10. TGF- $\beta$ secretion was found enhanced in lamina propria localised mononuclear cells in UC patients but decreased in CD patients [106]. Moreover, the expression of TGF- $\beta$ and its receptors was increased in intestinal cells of patients with IBD [107]. TGF- $\beta$ can have a detrimental effect and contribute to intestinal fibrosis in IBD patients which worsens disease outcomes [108]. In the context of endothelial function, TGF- $\beta$ has been suggested to increase endothelial permeability through activin receptor-like kinases (ALK) receptors $5[109,110]$. TGF- $\beta$ and ALK5 ligation is believed to activate TGF- $\beta$ induced ALK5 signalling, which leads to phosphorylation of Smad2 and Smad3, inhibition of angiogenesis, and increased endothelial permeability $[109,110]$.

Studies have indicated reduced IL-10 expression is a pathophysiological trait in IBD and an inducer of increased vascular permeability $[111,112]$. An IL-10 knockout mouse model of colitis shows increased endothelial permeability assessed by monolayer electrical resistance, increased albumin permeability, and reduced expression of occludin [112]. Moreover, endothelial cell dysfunction in IL-10 knockout mice is mediated by IFN- $\gamma$ activity, suggesting that endothelial barrier permeability is regulated reciprocally by IL-10 and INF- $\gamma$ [112].

Additionally, endothelial dysfunction corresponds with infiltration of leukocytes such as neutrophils and monocytes [103]. Accumulation of intestinal neutrophils and monocytes in the lamina propria induces release of mediators that jeopardise endothelial junctions via protease secretion and upregulation [103]. For instance, neutrophil-derived elastase proteins are elevated during IBD pathogenesis and can degrade endothelial junctional proteins such as cadherin [103, 113]. Overall, interactions between inflammatory mediators and gut antigens likely to enhance endothelial permeability and/or production of pro-inflammatory cytokines contributing to significant increases in systemic circulating inflammatory mediators. Serological studies have confirmed elevations in many immune mediators in the serum of IBD patients $[114,115]$. Evidence of circulating immune factors in the serum of patients with IBD is important given that it provides a route by which the gut can modulate distant sites such as the brain, which may induce mood disturbances such as depression.

\section{Humoral response in inflammatory bowel disease}

Several studies investigated serological cytokine signatures in paediatric patients with IBD in order to identify inflammatory biomarkers in the blood for diagnosing and evaluating IBD. Analytes included IL-13, IL-1 $\beta$, IL-4, IL-6, INF- $\gamma$, TNF- $\alpha$, IL-1 receptor antagonist, IL-12, IL-8 IL-5, IL-7, CCL11, IFN $\gamma$-induced protein 10 (IP-10), macrophage inflammatory protein, granulocyte-colonystimulating factor, and fibroblast growth factor (FGF) which were detected in sera acquired from IBD patients compared to healthy controls [114, 115]. Plasma infiltration of LPS with endotoxemia is present in $48 \%$ of CD patients and $28 \%$ of UC patients [116]. Moreover, 
sera levels of LPS and 1,3- $\beta$-D-glucan were found to be increased in patients with active $\mathrm{CD}$ compared to those in remission and controls, with sera TNF- $\alpha$ correlated with LPS and 1,3- $\beta$-D-glucan [117].

These studies provide a fundamental understanding of the biomarker signatures for IBD. However, inflammatory mediators have been postulated to induce systemic fallout resulting in other system compromises, including damage to the blood-brain barrier (BBB) in patients with IBD [118].

\section{Cytokine-induced damage to the blood-brain barrier}

Serological inflammatory mediators seen in IBD and animal models of colitis may impede $\mathrm{TJ}$ regulation in brain endothelial cells ultimately leading to a dysfunctional BBB marked by enhanced permeability [119]. In vivo and in vitro studies have shown that circulating cytokines can under some circumstances modulate expression of TJ proteins in cerebral endothelial cells $[120,121,122,123]$ (Fig. 2). For instance, IL-1 $\beta$ has been shown to suppress astrocytic sonic hedgehog (SHH) production [123]. In vitro, using a $\mathrm{SHH}$ conditioned media, $\mathrm{SHH}$, or an SHH signal agonist strengthens the BBB integrity by upregulation tight junction proteins, including claudin-5, ZO-1, and occludin [123]. These effects were abrogated by a SHH signal inhibitor [123].

Conversely, in vivo IL-10 attenuated the increased BBB permeability in rat models of severe acute pancreatitis by reducing brain microvascular endothelial cells apoptosis through a signal transducer and activator of transcription 3 (STAT3) pathway mediated downregulation of claudin-5 expression [124]. Similarly, IL-25 has been shown to preserve $\mathrm{BBB}$ and is expressed by brain capillary endothelial cells (BCECs) [125]. In vitro, IL-25 is

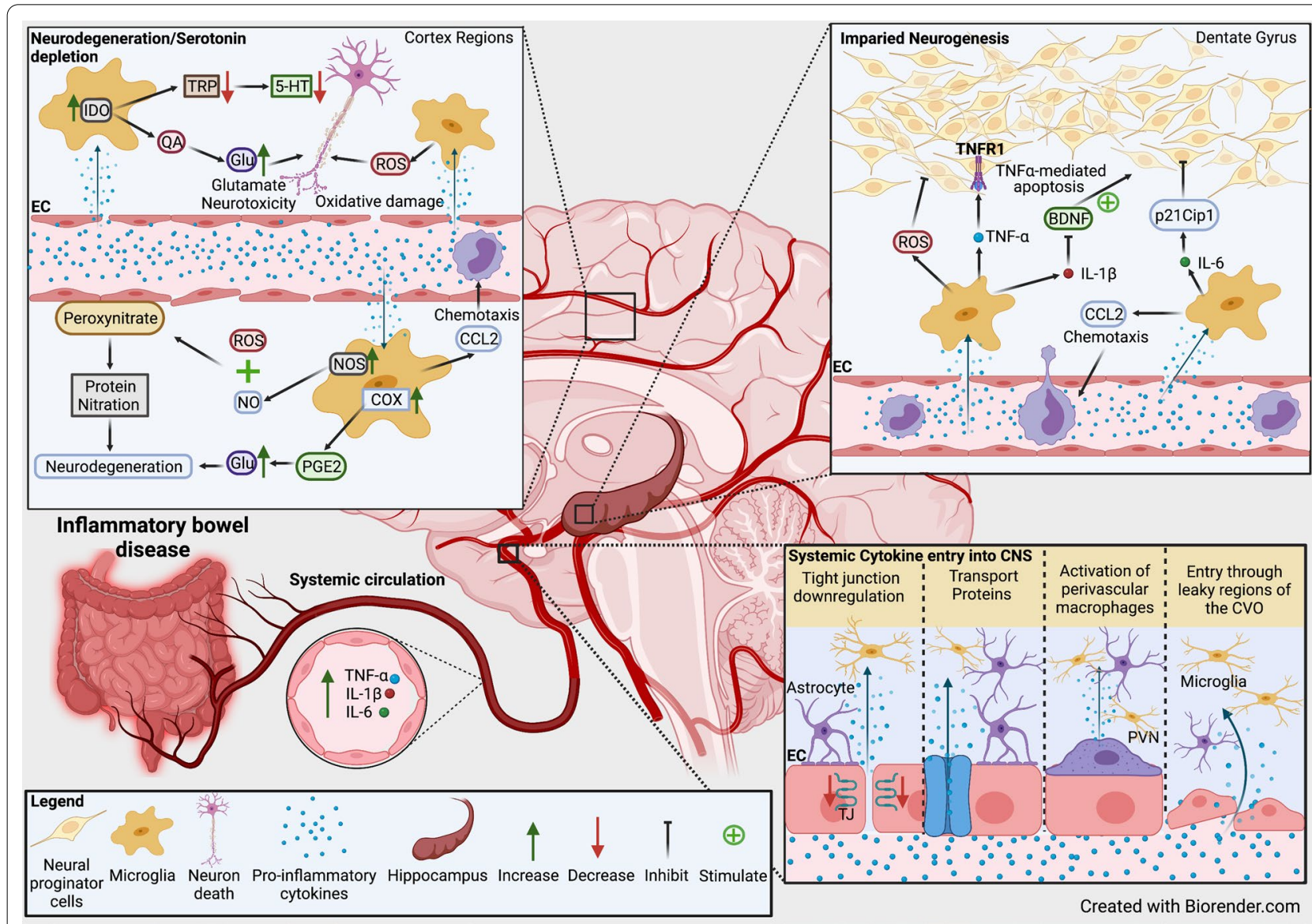

Fig. 2 Schematic diagram of neuroinflammatory changes seen in and postulated in human and animals with intestinal inflammation. Circulating inflammatory mediators enter into brain parenchyma through the suggested mechanisms whereby they may modulate local glia populations such as the microglia. Microglia can impact the various neurobiological correlates of depression including neurodegeneration, serotonin biosynthesis, and hippocampal neurogenesis. 5-HT 5-hydroxytryptamine (serotonin); BDNF brain-derived neurotrophic factor; CCL2 chemokine (C-C motif) ligand 2; CNS central nervous system; COX cyclooxygenase; CVO circumventricular organ; EC endothelial cells; Glu glutamate; IDO indoleamine-pyrrole 2,3-dioxygenase; IL interleukin; NO nitric oxide; NOS nitric oxide synthase; PGE2 prostaglandin E2; PVN perivascular macrophages; QA quinolinic acid; $R O S$ reactive oxygen species; TJ tight junction; TNF tumour necrosis factor; TNFR1 tumour necrosis factor receptor-1; TRP tryptophan 
downregulated by many pro-inflammatory cytokines, including TNF- $\alpha$, IL-1 $\beta$, and IL-6 [125]. IL-25 has been shown to restore the reduced expression of tight junction proteins, occludin, JAM, and claudin- 5 , induced by TNF- $\alpha$ in BCECs, leading to the restoration of TNF- $\alpha-$ induced BBB permeability [125]. Cytokine-induced regulation of $\mathrm{BBB}$ permeability may explain findings in animal models of colitis. A reduction in occludin and claudin-5 observed in the hippocampus and cortex of DSS-treated mice was suggested to be due to elevated serum IL- 6 levels [126]. Increased BBB permeability to tracers in animal models of intestinal inflammation may reflect modulation of cerebral endothelial cells by serologic immune factors $[127,128]$. A significant increase in BBB leakage predominantly in and around the circumventricular organs and focal areas of the brain parenchyma indicating impaired BBB integrity was observed in TNBS-induced colitis in Sprague-Dawley rats [128]. Moreover, enhanced infiltration of fluorescein, but not FITC-dextran, showing increased BBB permeability to smaller molecules, was observed in rabbits with either acetic acid or TNBSinduced colitis [127]. Importantly, this study confirmed that intestinal inflammation, not the treatment method, conferred $\mathrm{BBB}$ permeability given that both treatments enhanced permeability. Moreover, colitis has been associated with decreased transcription of ZO-1 (Tjp1) and claudin-5 (Cldn5) in the brain [129]. Transcription of TNF- $\alpha$, IL- $1 \beta$, and IL- 6 correlated with decreased transcription of Tjp1, but not $C l d n 5$ which could indicate that these cytokines may increase BBB permeability through ZO-1 downregulation [129].

Overall, these findings provide evidence that circulating pro-inflammatory cytokines result in injury to the endothelial cells of the BBB. Moving forward, diminished BBB integrity predisposes translocation of circulating neuroinflammatory mediators into brain parenchyma, which may affect the neuroglial networks and their regulation in the various regions of the brain.

\section{Cytokine entry and inflammatory responses in the central nervous system}

Circulating inflammatory mediators derived from the inflamed gut penetrate the brain following BBB dysfunction as noted in animal models of colitis. Circulating inflammatory mediators also affect the CNS through other mechanisms. For instance, they (i) enter through "leaky regions" in circumventricular organs [130] (Fig. 2), (ii) activate peripheral vagal nerve afferents that relay cytokine signals to the nucleus of the solitary tract and hypothalamus or HPA axis [131, 132], (iii) activate and induce the release of local inflammatory mediators by endothelial cells and perivascular macrophages in the cerebral vasculature [133] (Fig. 2), (iv) induce activation and diapedesis of peripheral monocytes/macrophages and $T$ lymphocytes into the brain parenchyma [134], and (v) through the utilisation of endothelial transporter protein channels [119] (Fig. 2). Whether through the listed mechanisms or via BBB dysfunction, inflammatory mediators may penetrate and modulate local CNS glial cells. Indeed, evidence of local immune activity in the brains of animals with colitis has been found $[126,135,136]$.

\section{Neuroinflammation in the CNS during colitis Inflammatory markers associated with neuroinflammation in colitis}

Several studies in animal models of colitis have identified inflammatory markers in the hippocampal and cortical brain regions $[126,135,136,137,138,139,140,141,14$ $2,143]$. There is a significant increase in IL-1 $\beta$ and IL-6 mRNA expression in the cortex and IL- $1 \beta$ and TNF- $\alpha$ in the hippocampus of mice with DSS-induced colitis [126]. This is accompanied by significantly higher serum levels of IL- 6 and TNF- $\alpha$ in mice with colitis $[126,135]$. Moreover, using TNBS-induced model of colitis in rats, Wang et al. (2010) reported intestinal morphological damage, increased myeloperoxidase activity, and increased mRNA and distribution of IL-6 in the inflamed colon and specific regions of the brain including the cerebral cortex and hypothalamus [144]. Neuroinflammatory changes are considered to be an indicator of alterations in animal behaviour in in vivo models of IBD [136]. In mice with dinitrobenzene sulfonic acid (DNBS)-induced colitis, a significant increase in the expression of TLR-2 and -4 , TNF- $\alpha$, IL- 6 and damage-associated molecular patterns like high mobility group box protein 1 (HMGB1), intracellular signalling proteins such as myeloid differentiation primary response 88 , and brain-derived neurotrophic factor (BDNF) was found in the hippocampal regions [136]. Enhanced innate immune responses in the brains of animal models of colitis have been associated with depressive behavioural traits seen as decreased mobility time in the forced swim and tail suspension tests, decreased grooming in the splash test and sucrose intake in the sucrose preference test [136]. Moreover, the inflammatory activity associated with anxiety and depression in mice with colitis was accompanied by alterations to hippocampal mitochondrial parameters [136]. These include decreased antioxidant glutathione (GSH) and adenosine triphosphate levels together with overproduction of reactive oxygen species (ROS) (Fig. 2), suggesting mitochondrial dysfunction and possible oxidative stress in the hippocampus of mice with colitis [136].

These findings are pertinent in IBD-associated depression given that brain metabolism impairments characterised by mitochondrial dysfunction and the generation of ROS have been implicated in the pathogenesis of 
depression and anxiety [145, 146]. Moreover, GSH, a major brain antioxidant that ameliorates oxidative species, is reduced in the prefrontal cortex of MDD patients [147].

In another study, mice with TNBS-induced colitis showed heightened behavioural despair and increased hippocampal TNF- $\alpha$, inducible nitric oxide synthase (iNOS), and nitrite expression [137]. In this study, only male mice were used in order to remove the confounding variable of high estrogen in females given its correlation with elevated serum cytokine production in chemicallyinduced colitis [148]. Future studies should determine the influence of estrogen on neuroinflammatory changes associated with colitis. Elevated iNOS activity in the hippocampus region and associated behavioural despair in this study [137], may suggest elevated nitric oxide (NO) production. $\mathrm{NO}$ is thought to play a central role in the neurobiology of depression [149]. In line with this, iNOSinhibitors reduce behavioural despair of mice with colitis [137]. NO-associated depression may be due to impaired neurotransmitter synthesis and/or neurodegeneration $[150,151]$. However, currently no studies in animal models of colitis have elucidated this mechanism. Indeed, in rats inhibition of NOS elevates levels of extracellular serotonin and dopamine in the ventral hippocampus, a major brain region correlated with depression [150]. During inflammatory pro-oxidant states, excessive NO in the brain can combine with superoxide anions to create peroxynitrate which induces neural degeneration and cell death via protein nitration [151] (Fig. 2). Given that there is evidence of ROS production and oxidative damage in animals with colitis [136, 137], further studies should investigate CNS changes indicative of oxidative damage in animals with colitis.

In a recently published study, DSS-induced colitis found upregulation of inflammatory-related proteins S100A8, S100A9 (also known as myeloid related protein (MRP) 8 and MRP14), and lipocalin-2 (Lcn2, also known as neutrophil gelatinase-associated lipocalin) in the brain. Though S100A9 and Lcn2 are upregulated in colitis, this is the first study to observe evidence of these proteins in the brain of mice with colitis [138]. Neutrophils, macrophages, and monocytes are the main source of these proteins, although other cells can also release them during infection [152]. The S100A8 and S100A9 proteins form a heterodimeric complex S100A8/A9 (also known as calprotectin), which has antimicrobial activity by sequestering trace metals essential for bacterial growth [152, 153]. Following inflammatory stimuli, these proteins are significantly upregulated and released into the extracellular environment, where they can activate immune and endothelial cells [152, 154]. Up regulation of S100A8 and S100A9 has been observed in many inflammatory diseases $[155,156,157,158]$, and faecal calprotectin is used as a marker for IBD severity as its level significantly correlates with intestinal inflammation [153, 159]. Paquinimod, an orally active immunomodulatory quinoline-3-carboxamide derivative, which blocks the interaction of S100A9 with TLR4 and receptors for advanced glycation end products (RAGE), prevented upregulation of $\mathrm{Lcn} 2$ and S100A8/A9 in the brain and S100A8/A9 in the colon and ameliorated symptoms of colitis [138, 153, 160, 161]. The upregulation of S100A8 and S100A9 in the brain could be related to the infiltration of peripheral inflammatory cells into the brain (monocytes and neutrophils) observed in this study [138]. However, S100A8 and S100A9 upregulation may be stressed-related as mice with chronic stress have upregulated genes encoding these proteins in the hippocampus [162].

Whilst S100A8 and S100A9 may play a central role in propagating neuroinflammation in colitis models, it has been suggested that NLR family pyrin domain containing 3 (NLRP3) protein activation may be involved [139]. NLRP3 largely functions as an intracellular sensor that detects microbial motifs, endogenous danger signals and environmental irritants [163]. Activation of NLRP3 results in the assembly and activation of the NLRP3 inflammasome, which leads to cleaving of inactive proIL- $1 \beta$ and pro-IL-18 into their active forms via caspase 1 $[163,164]$.

Increased NLRP3 inflammasome activity, microglial and astrocyte activation in the hippocampus and cortex, accumulation of gut-derived $\mathrm{T}$ cells along meningeal lymphatic vessels observed in the brains of wild type mice with DSS-induced colitis, were not found in NLRP3 knockout mice [139]. These findings could be the results of a NLRP3 facilitating dysfunction of the "glymphatic" system. The glymphatic system facilitates the entry of subarachnoid cerebrospinal fluid (CSF) into the brain interstitium where it mixes with brain interstitial fluid (ISF) $[165,166]$. CSF-ISF then flows through the interstitium, being drained via para venous pathways to the meningeal lymphatic vessels, reaching the cervical lymphatics $[165,166]$. Astrocytes allow the movement of fluid between paravascular spaces and the interstitium via water channels such as aquaporin-4 (AQP4), which requires the polarization of AQP4 [167]. This movement of fluid through the brain allows the removal of extracellular proteins, such as amyloid- $\beta$ peptide $(A \beta)$ and tau, from deeper areas of the brain, where interstitial solutes cannot normally reach the BBB $[165,168]$. Impaired glymphatic drainage may lead to $A \beta$ and tau protein accumulation, which has been associated with triggering and propagating neuroinflammation playing a central role in neurodegenerative conditions such as Alzheimer's 
disease [169,170,171]. Glymphatic dysfunction, leading to impaired clearance of $A \beta$ and aggravated cognitive decline seen in mice with DSS-induced colitis were attenuated in NLRP knockout mice [155]. This may be due to the binding of IL- $1 \beta$ to cognate receptors on astrocytes leading to the loss of AQP4 polarity [152]. Moreover, this study [139] and others [129, 138, 139] suggest a role of immune cells migrating from the gut to the brain in colitis-induced neuroinflammation. Meninges localised $\mathrm{T}$ cells have been shown to infiltrate the CSF, induce microglial activation, and enhance local pro-inflammatory cytokine production $[139,172]$. Additionally, other peripheral immune cells have been shown to be elevated in brain samples from animals with colitis including monocytes and neutrophils $[129,138]$. Whilst the evidence of neuroinflammation in colitis models is apparent, the underlying mechanisms still require exploration.

\section{Microglial cells during neuroinflammation in colitis}

After entering the CNS, inflammatory mediators may modulate local neuroglial cells in specific brain regions triggering neuroinflammation in animals with colitis $[126,136]$. Among the neuroglial cell populations, microglial cells can migrate and become activated during cytokine-induced neuroinflammation [173]. Microglia are derived from the embryonic mesoderm and are closely related to peripheral macrophages [174]. Functionally, they eliminate cell debris, remove damaged cells and destroy pathogenic agents [175]. Moreover, they support and regulate neurogenesis, maintain oligodendrocyte progenitor cells, neuronal morphology, neural circuitry pathways, and neuronal outgrowth and positioning in the developing brain. During neuroinflammation, the inflammatory milieu activates microglial cells initiating their immunological response [176, 177] (Fig. 2).

Several studies provide evidence that microglia are activated in the brains of mice with colitis $[126,135$, $138,139,140,141,142,143]$. In DSS-treated mice, significantly higher cortical and CA1 hippocampal immunofluorescence for a microglial marker, ionized calcium-binding adaptor protein-1 (Iba-1), has been observed [126, 141]. Since Iba-1 is a marker of both resting and activated microglia, an increase in Iba-1 immunoreactivity in DSS-treated mice was attributed to a change in microglia morphology and localisation as opposed to increased cell number and consistent with increased microglia reactivity [138]. Increased Iba-1 immunoreactivity may be transient as mice with DSSinduced colitis revealed increased hippocampal Iba-1 expression in acute colitis (day 7 post initial DSS treatment), and showed no difference after chronic colitis (day 29 post initial DSS treatment) [135]. Moreover, DSS administered to weaning (postnatal day 21) mice revealed enhanced gene expression for markers associated with microglia such as $I b a-1$, Nos 2 , and $I L-1 \beta$ along with increased microglia cell numbers, decreased numbers of dendritic processes, and decreased length of processes [140]. However, DSS was administered at the weaning stage, which is a critical point for the maturation of gut microbiota and may be due to gut dysbiosis [140, 178]. Furthermore, rats with TNBS-induced colitis, displayed microglial activation, increased excitability of hippocampal neurons, altered hippocampal glutamatergic transmission, and lowered seizure threshold [142, 143]. An intracerebroventricular injection of anti-TNF- $\alpha$ antibody and minocycline (an inhibitor of microglial/macrophage activation), reversed these findings, which may suggest CNS microglial/macrophage and/or TNF- $\alpha$ involvement in neuroinflammation associated with colitis [142, 143]. In another recent study, the number of microglia was significantly increased in the cortex and hippocampus in DSS-fed WT mice but reduced in the NLRP3 knockout mice [139].

Thus, the proinflammatory cytokines and NLRP3 appear to play a critical role in perturbation in microglia activity in these models. Whether these microglia are activated via mediators originating from the gut is yet to be confirmed and requires more investigation.

\section{Microglia activation, migration and neurodegeneration}

Increased expression of microglia, suggested in models of colitis, may be due to CNS-derived or circulating cytokines or antigens, which may activate neuroglial cells. As discussed, patients with IBD present with elevated serum levels of many pro-inflammatory cytokines and antigens inclusive of TNF- $\alpha$, IL- $1 \beta$, IL- 6 , and LPS $[114,115,116,117]$. If BBB dysfunction is indeed found in patients with IBD, these circulating factors may enter the brain parenchyma and alter microglial function conducive to the progression of neuroinflammation. Importantly we see evidence of upregulation of TNF- $\alpha$, IL- $1 \beta$, and IL- 6 in various brain regions of colitis models [126, $129,136,137]$, which may be sourced from or interact with neurons, microglia, and other cells.

Indeed, in vitro studies demonstrate the capability of cytokines to activate microglial cells and induce their release of pro-inflammatory and neurotoxic mediators $[176,177,179]$. For instance, stimulation of microglia with recombinant TNF- $\alpha$ induces upregulation of many pro-inflammatory mediators such as TNF- $\alpha$, Nos2, and Il-1 $\beta$ via an NF-kB p65 pathway [176]. As mentioned above, excessive NO may trigger neuronal cytotoxicity through protein nitration [180]. Whether NO neurotoxicity from microglia occurs in the CNS of colitis models is yet to be explored, but, as discussed earlier, 
TNBS-induced colitis was associated with a significant increase in hippocampal TNF- $\alpha$ and iNOS protein levels which could reflect reactive microglia activity [137]. Furthermore, stimulation of mouse microglial cell line BV-2 with IL-1 $\beta$ induces expression of pro-inflammatory markers such as COX-2, chemoattractant protein-1 (CCL2), and IL-6 via a PI3K/Akt pathway [177]. This pathway and associated inflammatory markers could be relevant in colitis as NLRP3 inflammasome activity (critical for caspase 1-dependent release of IL-1 $\beta$ and IL-18) in the CNS has been implicated in the exacerbation of neuroinflammation by DSS-induced colitis in aging mice [139, 181]. Moreover, increased levels of mRNAs for TNF- $\alpha$, IL- $1 \beta$ and COX- 2 protein expression were found in isolated rat cerebral cortex microglial cell cultures treated with recombinant IL-6 compared to untreated control [179]. COX-1 and -2 catalyse the formation of prostaglandins, thromboxane, and levuloglandins [182]. In vivo, systemic TNF- $\alpha$ and LPS administration activated microglia and increased expression of brain proinflammatory factors in WT mice, but not in TNF R1/R2 deficient mice [183]. Indeed, this may be consistent with studies that observed normalisation of synaptic transmission following either anti-TNF- $\alpha$ or minocycline treatment in animals with colitis [142, 143, 184].

Enhanced prostaglandin activity might contribute to the mechanisms involved in the increased BBB permeability observed in models of colitis [126, 127]. Different prostaglandin receptors appear to have varying functions in terms of BBB permeability. In ischemic stroke models, pharmacological or genetic inhibition of PGE2 receptors suggests that EP1 and EP3 receptors contribute to BBB breakdown observed in these models $[185,186,187]$. EP4 was reported to attenuate BBB dysfunction induced by stroke $[188,189]$. However, in animals administered with LPS, prostaglandins show varying effects including blocking, enhancing, or having no effect on the actions of LPS on BBB permeability [190,191,192]. Furthermore, systemic LPS challenge has been shown to induce upregulation of prostaglandin enzyme COX-1 in microglia and perivascular macrophages with PGE2 increase seen primarily in the hippocampus and thalamus [193]. Mice with DSS-induced colitis exhibited more anxiety and less social behaviour than control mice and occurred in parallel with increased circulating IL-6, NPY, and IL-18 levels as well as an increase in hypothalamic Cox-2 mRNA [194]. In a recent study using DSS-induced colitis, elevated expression of the Ptgs2 gene, which encodes COX2, was noted [138].

Systemic LPS challenge in mice elicits the increased amounts of CCL2 mRNA and protein in the hypothalamus and hippocampus, in conjunction with upregulation of chemokine receptor 2 (CCR2) expression by microglia [195]. CCR2 studies in the CNS of mice with colitis are very limited and require further investigation. However, no changes in seizure threshold in colitis mice with impaired CCR2 functioning were found, which suggested that monocytes do not play a major role in colitisinduced neuronal hyperexcitability [129]. CCR2 appears in two isoforms (CCR2A and CCR2B) with CCR2B being the dominant isoform making up $90 \%$ of all CCR2 expression and is observed on microglia, astrocytes, and neurons, while CCR2A is observed in certain mononuclear and smooth muscle cells $[196,197,198]$. CCL2-CCR2 axis can induce the secretion of pro-inflammatory cytokines, such as IL-1 $\beta$ and IL-18 by microglia [197]. Moreover, CCR2 appears critical for microglial accumulation as indicated in CCR2 knockout models [199]. Studies should entice to investigate whether CCR2 is upregulated in brain tissue from animals with colitis, which may help elucidate possible mechanisms underpinning microglial activity seen in animals with colitis. Given that in vitro and in vivo studies evidence the capacity of circulating inflammatory mediators and endotoxins in inducing microglial changes, it may be plausible that alteration in microglia noted in animal models of colitis could be due to systemic infiltration of antigens and immune mediators. Moreover, COX2, PGE2, and CCR2 would be plausible future targets to investigate in the CNS of animals with colitis, given their role in the progression of events relevant to neuroinflammation.

\section{Mechanisms of colitis-associated suppression of hippocampal neurogenesis}

Impaired hippocampal neurogenesis has previously been associated with microglial cell activity leading to depression and maybe a neurobiological mechanism underlying IBD-associated depression [200]. The association between reduced neurogenesis and depression in humans can only be inferred through reduced hippocampal volume noted in depressed individuals [201]. However, post-mortem cellular changes in depressed humans revealed alterations in the neuropil, altered fluid content, and changes in granule cell and pyramidal cell density. [202]. This may be responsible for hippocampal volume changes in humans. Further research to confirm neurogenesis as a neurobiological correlate of depression is needed.

Adult neurogenesis mainly occurs in the subgranular (SGZ) and subventricular zones in the dentate gyrus of the hippocampus resulting in the formation of new granule cells from neural progenitor cells [203]. Microglia play a vital role in facilitating the complex process of neurogenesis. In vitro studies have demonstrated that microglial conditioned media enhance precursor cell differentiation, neuroblast production, and neuronal 
survival [204, 205]. In addition, microglia are implicated in eliminating apoptotic neuroblasts and adult neurons through phagocytosis, which is vital given that most of the newborn cells undergo death by apoptosis within the first 1-4 days of their life [206].

Given that increased microglial expression is noted in in vivo animal models of IBD [126, 135,138,139,140,141,142,143], microglia-facilitated impairment of neurogenesis may be responsible for triggering or potentiation of colitis-associated depressive symptoms. Imaging studies show an increase in gray matter volume in the hippocampus of $\mathrm{CD}$ patients which may be related to immune activation that induces alterations in glial cells activity [207]. There are limited studies confirming hippocampal dysfunction because of activated microglial cells in animal models of colitis. However, enhanced microglial cell activity in the hippocampus is correlated with a reduction in a neuronal marker, doublecortin (DCX), associated with reduced neurogenesis and behavioural abnormalities in mice with DSS-induced colitis [140]. Moreover, it has been speculated that reduced neurogenesis seen in animals with colitis may be induced by cyclin-dependent kinase inhibitor p21 ${ }^{\text {Cip1 }}$ (p21) activity in the hippocampus. Functionally, p21 restrains cell cycle progression and arrests the cell in the G1 phase [208]. p21 can be induced in early neuronal progenitors and immature neurons in the SGZ and can function to limit these cells' proliferation and ultimately suppresses neurogenesis $[135,204$, $209,210]$. In addition, acute systemic inflammation and pro-inflammatory cytokines, originating from microglia or other cells, can increase p21 expression and restrain hippocampal precursor cells of neuronal lineage in the SGZ [210]. In a study using mice with DSS colitis, acute colitis was correlated with increased p21 expression in the hippocampus [210]. However, in the chronic phase of inflammation, a fourfold increase in p21 mRNA levels was noted [210]. Markers of neuronal stem/early progenitor cells, inclusive of nestin and brain lipid-binding protein, and DCX were downregulated [210]. The nuclear protein Ki-67 and marker of cell proliferation co-labelled with DCX showed a decrease in number during chronic colitis in the SGZ [210].

Microglial-associated cytokines IL-1 $\beta$, TNF- $\alpha$, and IL-6 have been shown in vitro to induce p21 expression in differentiating neuronal progenitors and may be partly responsible for the above findings [210] (Fig. 2). Importantly, pro-inflammatory cytokines noted in the hippocampus of animals with colitis, whether secreted by microglia or other cells, or peripherally sourced, have been suggested to suppress neurogenesis through different mechanisms. For instance, Cacci et al. (2005) revealed that the co-culture of an embryonic hippocampus-derived HiB5 cell line with LPS-activated microglia results in TNF $\alpha$-mediated apoptosis suppressing neuronal development and differentiation [211]. Moreover, altered hippocampal neurogenesis is seen in vivo in mice with depleted TNF receptor (TNFR) 1 and TNFR2 [212]. TNFR knockout mice showed an increased rate of neural progenitor proliferation and neurogenesis in the hippocampus [212]. This study suggests that microglial activation may suppress hippocampal neurogenesis via the release of TNF- $\alpha$ binding to TNFR1 on hippocampal progenitors, which is known to be related to a fas-associated protein with death domain-caspase-8/3 which induces apoptosis likely contributing to impaired generation of new neurons [213] (Fig. 2). Increased hippocampal expression of TNF- $\alpha$ has been noted in DNBS, TNBS, and DSS-induced colitis [129, 135,136,137, 142, $143,204]$. Importantly, in DSS-colitis, cleaved caspase- 8 was found upregulated in the brain and cleaved caspase- 3 was found upregulated in the hippocampus, which may suggest the action of the above pathway $[135,138]$.

Cytokine or antigen challenge can induce microglia to release IL-1 $\beta$, which has been implicated in the modulation of neurogenesis. Studies have shown IL-1R1 expression in vitro in rat embryonic forebrain NPCs [214] and adult rat hippocampal cells [215]. The binding of IL- $1 \beta$ is associated with decreased proliferation in hippocampal progenitor cells [216]. Furthermore, mice with chronic stress-induced depression display increased IL-1 $\beta$ expression in the dorsal hippocampus that decreases dentate gyrus hippocampal neurogenesis [217]. Moreover, IL-1 $\beta$ dysregulation dampens BDNF secretion associated with neurodegeneration [218]. Reduced BDNF mRNA expression in the dentate gyrus and CA3 region of the hippocampus was seen in mice exposed to contextual fear conditioning followed by social isolation [218]. In vivo treatment of contextual fear-conditioned mice with an IL-1R antagonist, suppressed IL- $1 \beta$ signalling improving BDNF expression and preventing impairments in hippocampally-dependent contextual fear conditioning tests following social isolation [218] (Fig. 2). Limited studies in models of chemically-induced colitis provide evidence that BDNF expression is reduced in the hippocampus (DNBS) and forebrain (DSS) with IL-1 $\beta$ expression elevated in DSS models [135, 136, 138].

Alteration in hippocampal neurogenesis in IBD animal models may be due to abnormal excitatory synaptic properties in the hippocampus. Hippocampal tissue from Sprague-Dawley rats with TNBS-induced colitis revealed enhanced Schaffer collateral-induced excitatory field potentials in CA1 stratum radiatum [142]. Schaffer collaterals are axon collaterals from CA3 pyramidal cells projecting to CA1 area [219]. This was associated with larger-amplitude miniature excitatory 
postsynaptic currents (mEPSCs), but unchanged mEPSC frequencies and paired-pulse ratios, suggesting altered postsynaptic effects. Both $\alpha$-amino-3-hydroxy5-methyl-4-isoxazole propionic acid receptor (AMPA)and $\mathrm{N}$-methyl-D-aspartate (NMDA)-mediated synaptic currents were enhanced in the rats [142]. Moreover, AMPA-mediated currents revealed increased contribution of GluR2-lacking receptors and mRNA and protein levels of the glutamate ionotropic receptor AMPA type subunit 2 (GluR2) subunit were reduced in the hippocampus [142]. Interestingly, the chronic administration of minocycline, a microglial/macrophage activation inhibitor, lowered the level of TNF- $\alpha$ in the hippocampus and completely abolished the effect of peripheral inflammation on observed transient electrical signals and synaptic plasticity [142]. The authors had previously shown in vivo that enhanced brain excitability during colitis requires both elevated cytokines TNF- $\alpha$ and microglial activation [143]. Indeed, TNF- $\alpha$ has been evidenced to facilitate the insertion of GluR2lacking AMPA receptors in the membrane [204, 220, 221].

The increase in hippocampal NMDA and AMPA receptors may make neurons more prone to glutamateinduced excitotoxicity, though no evidence of increased release or availability of glutamate was found [142]. The presence or absence of the GluR2 subunits determines the $\mathrm{Ca}^{2+}$ permeability of the AMPA receptor [222]. The low expression of GluR2 enables the formation of AMPA receptors with high $\mathrm{Ca}^{2+}$ permeability, which contributes to neuronal degeneration [222,223,224]. In relation to NMDA receptors, the $2 \mathrm{~A}$ and $2 \mathrm{~B}$ subtypes are widely distributed in the hippocampus. Moreover, quinolinate phosphoribosyltransferase, which converts NMDA agonist quinolinic acid (QA) into nicotinamide adenine dinucleotide, is low in the hippocampus reducing the capacity to clear QA in the hippocampus [225]. QA may then function as an excitotoxin and damage the hippocampal neurons [207].

It has been revealed that activation of adenosine monophosphate-activated protein kinase (AMPK) can enhance hippocampal neurogenesis through the AMPK/ BDNF pathway [226]. Furthermore, there is evidence indicating that activation of AMPK attenuates inflammation in the CNS [227]. Neuroinflammation and suppression of hippocampal neurogenesis in models of colitis could be due to impairments in the AMPK/BDNF signalling pathway. A study tested this theory using an activator of AMPK, called liver hydrolysate ( $\mathrm{LH})$, that has been shown to increase hippocampal neurogenesis through the AMPK/BDNF pathway and has an antidepressant effect in an animal model of depression [228]. In a study using DSS-treated mice, LH prevented depressive-like behaviours and enhanced hippocampal neurogenesis through the AMPK/BDNF pathway and hippocampal activation of microglia and astrocytes [229].

HMGB1 expression could play a critical role in synaptic dysfunction and/or impaired neurogenesis in colitis models. HMGB1 is a 215 residue protein that consists of two consecutive L-shaped basic domains referred to as HMG boxes and a 30 amino-acid long tail with acidic properties [230]. HMGB1 is commonly found in the nucleus where it binds to the minor group of B type DNA and distorts and bends the double helix DNA of 90 degrees or more. HMGB1 can function to modulate transcriptional activity through its interaction with transcription factors such as p53 and nuclear factor kappa-light-chain-enhancer of activated B cells (NF-kB) [230]. Moreover, HMGB1 can function as a damage-associated molecular pattern (endogenous danger molecule released from damaged or dying cells inducing immune response by interacting with pattern recognition receptors) and bind to hippocampal TLR-4 inducing the activation of NF- $\mathrm{KB}$ and Activator protein 1, which facilitate the synthesis of proinflammatory mediators such as IL- 6 , TNF- $\alpha$ and iNOS [231]. As mentioned above, the induction of pro-inflammatory cytokines, including IL-1 $\beta$, TNF- $\alpha$, and IL-6, have been shown to inhibit hippocampal neurogenesis [210,211,212, 216, 217]. Using an experimental model of chronic cerebral hypoperfusion in rats, anti-HMGB1 neutralizing $\mathrm{Ab}$ reduced hippocampal glial activity and inflammatory cytokines, such as TNF- $\alpha$, IL-1 $\beta$, and IL-6, as well as increased antioxidants superoxide dismutase and catalase, which was associated with improved CA1 neuronal survival and cognitive tasks [232].

In DNBS-induced colitis, increased expression of the $H M G B 1$ gene in the hippocampus has been suggested to be detrimental to hippocampal neurogenesis and function [136]. Additionally, HMGB1 has also been shown to be involved in hippocampal neurobiological functions including memory and long-term potentiation [233, 234]. HMGB1 can inhibit hippocampal long-term potentiation and memory via TLR-4 and RAGE, which is accompanied by activation of NF- $\mathrm{kB}$ and c-Jun N-terminal kinase [233].

Overall, pro-inflammatory cytokines, HMGB1, glial cells and, synaptic dysfunction could independently or in unison be responsible for alterations in neurobiological pathways which promote suppression of neurogenesis seen in colitis [140, 210]. However, the exact mechanisms whereby colitis can alter pathways and the relationship between contributing factors is yet to be determined.

\section{Microglia and the serotonin-kynurenine pathway}

Impairments in serotonin biosynthesis could be an underlying mechanism behind behavioural changes seen 
in animals with colitis. However, the serotonin biosynthesis theory of depression is still debated. In treatment for tuberculosis and schizophrenia, iproniazid (inhibits the breakdown of monoamines) and imipramine (blocks serotonin and norepinephrine transport) were found to reduce depressive symptoms [235]. Moreover, reserpine, which can deplete monoamines, was implicated in triggering depressive symptoms. These observations helped formulate the theory that depression is caused by the depletion of monoamine transmission [235, 236]. But whilst serotonin biosynthesis has been implicated in depression pathogenesis, many studies have found evidence contradicting this theory. For instance, selective serotonin reuptake inhibitors increase extracellular serotonin within short periods following administration $[237,238]$, however, the beneficial antidepressant effects arise following weeks of continuous treatment [239]. Moreover, reducing serotonin synthesis through dietary reductions in tryptophan fails to induce depression in non-depressed individuals [240]. This review discusses the microglia-associated reduction of serotonin bioavailability as a possible mechanism underlying IBD-associated depression, however, caution should be taken as this proposed theory is still debated.

Microglial cell activity can modulate the serotoninkynurenine pathway which plays an important role in depression [241]. Microglia express the tryptophan-catabolizing enzyme IDO in the presence of pro-inflammatory cytokines [242]. IDO converts tryptophan (amino precursor of serotonin [5-HT, 5-hydroxytryptamine]), into kynurenine $(\mathrm{KYN})$ which can then be catabolized by the enzyme kynurenine 3-monooxygenase (KMO) into excitotoxic metabolites 3-hydroxy-kynurenine (3HK), 3-hydroxy-anthralinic acid, QA, and finally the end-point co-enzyme nicotinamide adenine dinucleotide [243]. Conversely, KYN can also be metabolized through a neuroprotective pathway to kynurenic acid (KYNA) by the enzyme kynurenine-aminotransferase (KAT) [243]. Importantly, KMO is expressed by leukocytes such as monocytes, macrophages, and microglial cells, whereas KAT is present in astrocytes [242, 244]. Quinolinic acid reduces the expression of astrocyte glutamate reuptake pumps while stimulating release of glutamate from astrocytes which may result in glutamate neurotoxicity and neurodegeneration [245, 246] (Fig. 2).

Studies linking colitis with the TRY/KYN alteration in the CNS are limited. However, mice infected with a parasite Trichuris muris (T. muris), which induces colitis, have higher levels of serum kynurenine and an increased kynurenine/tryptophan ratio when compared to non-infected mice [247]. Moreover, T. murisinfected mice displayed behavioural abnormalities as assessed by a light/dark preference test and elevated levels of circulating pro-inflammatory cytokines such as TNF- $\alpha$ and IFN- $\gamma$ which were all alleviated with either a corticosteroid (budesonide) or an anti-TNF- $\alpha$ agent (etanercept) interventions that normalized circulating kynurenine levels [247]. Similarly, mice with DSS and TNBS colitis revealed a reduction in serum levels of tryptophan and increased intestinal expression of IDO [248, 249]. In humans, serum obtained from CD and control participants elucidated a marked reduction in tryptophan and an increased K/T ratio in active $C D$. Whether these findings are due to upregulation in microglial IDO is unknown. Indeed, increased IDO-1 gene expression was observed in the medial prefrontal cortex (PFC) of mice with colitis, however, this was accompanied by reduced microglia expression [250]. It should be considered that alterations noted in serum tryptophan and $\mathrm{K} / \mathrm{T}$ ratios could be due to changes in IDO- 1 expression in the gut. IDO overexpressed has been noted in lesional biopsies from patients with IBD with CD123+dendritic cells being the primary cell to express the enzyme [251]. Moreover, although appearing detrimental in the context of depression, IDO expression appears beneficial in suppressing intestinal inflammation. In TNBS colitis, inhibition of IDO results in more severe colitis and a significantly increased colonic pro-inflammatory cytokine expression [249]. This may be due to enhanced availability of tryptophan and increased 5-HT synthesis in the intestines. Indeed, 5- HT has been implicated in worsening colitis as mice with tryptophan hydroxylase- 1 knockout experienced reduced 5-HT in the GI tract and had reduced severity of DSS-induced colitis [252]. It appears that there may be paradoxical findings in the brain and gut whereby reduced serotonin worsens depressive symptoms and increased serotonin contributing to more severe colitis. Overall, more research is warranted to elucidate the presence of IDO-expressing neuroglia cells in the brains of animals with colitis and whether serum levels of tryptophan and K/T ratio alteration noted in IBD and animals with colitis contribute to/or are caused by IDO expression in the CNS.

\section{HPA axis dysregulation in IBD}

The HPA functions to coordinate neural, endocrine and immune responses to diverse stimuli that threaten physiological homeostasis. Glucocorticoids, corticosteroid hormones are the final products of HPA axis activation and function to alter cellular metabolism and the immune system [253]. The homeostatic regulation of the HPA involves bi-directional communication and integration between the brain, endocrine and immune systems [254]. The functional balance between pro- and antiinflammatory mediators is critical for control of the HPA 
axis and the dysregulation in its activity, a characteristic of numerous chronic inflammatory diseases [254].

Following the immunological or emotional challenge, the hypophysiotropic neurons in the medial paraventricular nucleus (PVN) can synthesise and secrete the corticotrophin-releasing factor (CRF) into the hypophysial-portal circulation [255, 256]. CRF can then access CRF-Receptor-1 at the anterior pituitary corticotropes and stimulate the rapid release of adrenocorticotropic hormone (ACTH) [257]. ACTH enters systematic circulation and binds to melanocortin type 2 receptor in parenchymal cells of the adrenocortical zona fasciculata, which induces the release of glucocorticoids, including cortisol in humans and corticosterone in rodents [257, 258].

Inflammatory mediators, which are abnormally elevated in the serum of IBD patients $[114,115]$ and the brains of animals with colitis [126, 135,136,137,138,13 $9,140,141,142,143]$, can also interact with the HPA axis at various points. These include (i) stimulation of vagal nerve afferents [259]; (ii) interaction with brain ECs, which induce the synthesis/release of secondary messengers such as prostaglandins [260, 261]; (iii) crossing the $\mathrm{BBB}$ at "leaky" regions such as the fenestrated endothelium circumventricular organs or areas where BBB dysfunction is present, whereby they activate neurons that project to the hypothalamus [262]. Inflammatory cytokines can also act directly on glucocorticoid receptors (GR) and suppress their function. For instance, activation of mitogen-activated protein kinase pathways such as ERK, JNK, and p38 by inflammatory cytokines can inhibit GR function by either directly phosphorylating GR at serine-246, indirectly via a GR co-factor, or by inhibiting translocation of the GR from the cytoplasm to the nucleus [263,264,265]. Further, cytokines can activate NF- $k B$, which is implicated in the inhibition of GR by the physical association in the nucleus [266].

Modulation of the HPA axis by circulating cytokines may explain evidence of a dysfunctional HPA axis in IBD patients. The cytokine IL-6, which induces cortisol secretion [267], shows no relationship to serum concentrations of cortisol in IBD patients [268, 269]. Impaired regulation of IL-6 plays a crucial part in the uncontrolled intestinal inflammatory processes in IBD. Increased formation of IL-6-sIL-6R complexes with gp130 on the membrane of CD4+T-cells causes a STAT3-mediated transcription of anti-apoptotic genes, such as $B c l-x l$ resulting in T-cell expansion contributing to the perpetuation of chronic intestinal inflammation $[270,271,272]$. It has been suggested that the ANS and HPA axis are uncoupled in IBD patients as high morning vagal tone is associated with a low evening cortisol level in healthy subjects but no association was found in IBD patients [273]. Additionally, plasma NPY, a marker of ANS activity, was not positively correlated with serum cortisol in IBD patients as was observed in healthy controls [274]. In vivo, mice with DSS-induced colitis presented with brain region-specific alterations in HPA axis-related peptides, glucocorticoid receptor gene expression, and factors including NPY, NPY receptor Y1, CRF, CRF receptor 1, and BDNF [275, 276]. Interestingly, chemical stimulation with glutamic acid of the PVN, which is a major source of brain CRH, alleviated TNBS-evoked colitis as assessed by a reduction in colonic damage scores and levels of IL- 6 and IL-17 [277]. A possible mechanism underlying these findings could be neuroinflammatory damage in brain regions implicated in the regulation of the HPA [278, 279]. Direct inflammatory insult regions of the brain could be a potential mechanism underlying HPA axis dysfunction in IBD and is supported by studies implicating neuroinflammation in animals with colitis.

A major brain region of the ANS and the stress response is the locus coeruleus (LC), which is a cluster of NA-containing neurons located in the upper dorsolateral pontine tegmentum of the brainstem [280]. Nerve fibres from the LC provide the sole source of NA to the cortex, hippocampus, cerebellum, and thalamus [280]. CRF-releasing neuronal afferent originating from the PVN project to the $\mathrm{LC}$ and noradrenergic neurons from the LC project to the PVN [281,282,283]. A positive feedback loop appears to exist between the HPA axis and the ANS with the firing rate of LC neurons increased by CRF which induces the release of NA by LC neurons $[284,285,286]$. Consequently, NA has then been shown to promote CRF mRNA expression in the PVN [287]. Consistent with this, lesions of the LC attenuate the HPA axis response to acute restraint stress but not chronic stress [288]. Importantly, it has been suggested that the Central Autonomic Network (CAN), which includes the PFC and limbic structures such as the hippocampus can exert tonic inhibitory control of the ANS, HPA axis, and amygdala $[289,290,291,292]$.

\section{The central autonomic network and neuroinflammation}

The activity level of the ANS and HPA axis, represented by peripheral measures, such as heart rate and cortisol variability, is associated with the activity of the PFC and amygdala, respectively [293]. The amygdala is under tonic inhibition from gamma-aminobutyric acid (GABA)ergic fibres projecting from the PFC [293]. The medial and central amygdaloid nuclei are believed to stimulate the HPA axis [294]. Hence, the uncoupling between the ANS and HPA axis observed in IBD patients may be due to inflammatory insult in the PFC, as seen in animal models of IBD, which consequently impairs its role in tonic inhibition of the LC, amygdala, 


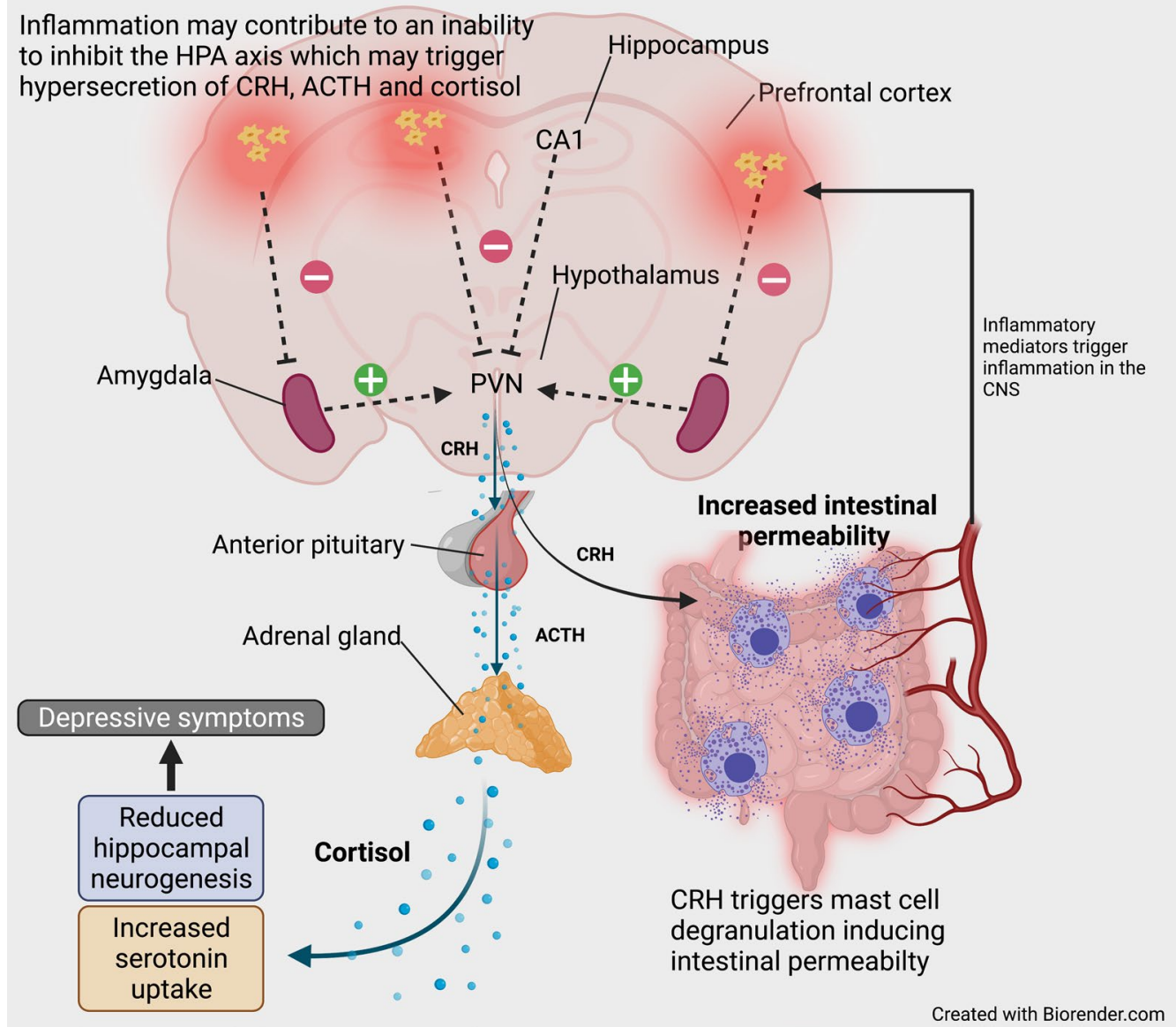

Fig. 3 Schematic representation of neuroinflammatory-induced impairment of the HPA axis functioning. Resultant neuroinflammation associated with animal models of colitis may induce damage or neurobiological alteration in important regions associated with inhibition of the HPA axis. This may trigger the aberrant secretion of hippocampal, pituitary, or adrenal hormones triggering worsening of intestinal and cortical inflammation and depressive symptoms. ACTH adrenal corticotrophin-releasing hormone; CA1 cornu ammonis 1; CNS, central nervous system; CRH corticotrophin releasing hormone; HPA hypothalamic-pituitary-adrenal; PVN paraventricular nucleus

and HPA axis (Fig. 3). However, whether neuroinflammation or other factors contribute to proposed PFC hypoactivity in IBD patients has yet to be elucidated. Indeed, inflammation in the PFC may produce damage with varying implications on glucocorticoid release depending on regions of the PFC impacted. For instance, lesions of the prelimbic divisions (PLD) and anterior cingulate $(\mathrm{AC})$ of the mPFC enhance adrenocorticotropic hormone and corticosterone secretion and induce PVN activity as determined by the neuronal activity marker c-fos following restraint stress $[295,296,297]$. However, lesions of the right infralimbic cortex reduce corticosterone release caused by restraint stress [298]. Importantly, the PFC is suggested to be involved in the negative feedback system, which inhibits the HPA axis. GR density is high layers II, III, and VI of the PFC [299]. In support of this function, the release of $\mathrm{ACTH}$ and corticosterone following restraint stress was found attenuated after infusion of glucocorticoids into the mPFC $[257,297,300]$.

Studies investigating neuroinflammation in the CNS of animals with colitis should explore regions such as the PLD and AC given their suggested role in the inhibition of the HPA axis.

Studies have implicated the hippocampus in inhibition of the HPA axis [301, 302], supported by findings that the stimulation of the hippocampus decreases glucocorticoid secretion in rats and humans [303, 304]. This may be relevant to HPA axis dysfunction in IBD given that animal models of colitis provide evidence of reduced hippocampal neurogenesis, enhanced oxidative stress, mitochondrial dysfunction, and impaired synaptic transmission [136, 140, 142, 143]. Indeed, damage to the hippocampus appears to trigger a disrupted HPA response. For instance, hippocampectomy, fimbria-fornix lesions, or excitotoxic lesions increase corticosterone and/or CRH 
secretion [305,306,307,308]. It is believed that the CA3, dentate gyrus (including CA4), and subiculum region of the hippocampus are involved in the inhibition of the HPA axis [309], whereas the dorsal hippocampus appears to excite the HPA axis [310]. Future studies should investigate the role of these brain regions in HPA axis dysfunction evidenced in IBD patients and colitis models and ascertain whether neuroinflammatory events precipitate this dysfunction. While it could be proposed that inflammation in key regions of the brain is responsible for HPA axis dysfunction, other factors such as stress could be involved.

\section{Stress and IBD}

IBD patients have been shown to have a high incidence of psychological distress and comorbidities, such as depression, anxiety disorders, obsessive-compulsive disorders, and bipolar disorder [311, 312]. Stress has also been suggested to increase the susceptibility of individuals to IBD. Approximately two-thirds of patients who had both anxiety disorder and IBD developed psychiatric symptoms predating the IBD diagnosis by over 2 years with the onset of IBD also arising much earlier in patients with lifelong anxiety [313]. Recurrence and aggravation of IBD symptoms have also been shown following stressors with high perceived stress suggested as impacting the frequency of symptomatic flares [314].

Stress likely plays a role in IBD generation, recurrence, or aggravation due to impact on CRF. Stress directly influences the PVN to release CRF which can bind to CRF receptors expressed in the brain and the gut [257, 315]. Ligation of gut CRF receptors with CRF can modulate intestinal secretion, peristalsis, and the mucosal barrier permeability [316]. Moreover, CRF can trigger degranulation of mast cells that leads to enhanced mucosal permeability and promotion of pathophysiological mechanism underlying IBD [317]. Consistent with this, chronic stress in WT rats can induce intestinal barrier dysfunction, inflammatory cell infiltration, and mast cell proliferation and activation [318]. However, intestinal dysfunction in chronically-stressed mice has been abrogated in mast cell-deficient rats [318]. Further, using a mouse model of chronic restraint stress, the neuropeptide substance $P$ and its receptors increased $\mathrm{CRH}$ expression and CRH release by eosinophils that resulted in a mast cell-mediated increase in epithelial barrier dysfunction [319].

Overall, whether arising due to colitis-induced central neuroinflammation, elevations of serum inflammatory mediators, or the neuroendocrinology of the stress response, inappropriate glucocorticoid secretion could have various implications in the brain and gut inflammation.

\section{Glucocorticoids: good or bad in IBD?}

Glucocorticoids are known for their mainly immunosuppressive action. Glucocorticoids induce the synthesis of anti-inflammatory proteins such as IL-10, lipocortin 1, and IL-1 receptor antagonists, and promote apoptosis in inflammatory cell types such as $\mathrm{T}$ cells and eosinophils [320, 321]. Moreover, glucocorticoids can inhibit the transcription factors AP-1 and NF- $k B$ reducing the synthesis of several pro-inflammatory cytokines and chemokines including IL-1, IL-6, and TNF- $\alpha$ [322]. Treatment of severe exasperations of intestinal inflammation in IBD often involves corticosteroids, such as prednisone, hydrocortisone, and dexamethasone (DXM), to induce remission [323].

However, glucocorticoid hormones may increase intestinal inflammation and potentially worsen neuroinflammation. For instance, glucocorticoids induce the synthesis of NLRP3 inflammasome mRNA and protein and enhance ATP-mediated release of pro-inflammatory cytokines such as IL-1 $\beta$, TNF- $\alpha$, and IL-6 [324]. Moreover, glucocorticoids induce expression of TLR and secretion of inflammatory mediators by endothelial cells via P2Y2 purinergic receptors [325, 326]. They also modulate significant neurobiological mechanisms correlated with depression. Foetal hippocampal progenitor cells treated with corticosterone display reduced proliferation and differentiation, whereas DXM treatment only suppresses proliferation [327] (Fig. 3). Furthermore, mice treated with DXM demonstrated a cyclin-dependent kinase 5 phosphorylation of an axonal transport protein huntingtin, preventing cortical delivery of BDNF to the hippocampus resulting in impaired neurogenesis [328] (Fig. 3). Cortisol activates tryptophan 2,3-dioxygenase (TDO) which, like IDO, converts tryptophan into kynurenine [329]. These findings become even more relevant when one notes that cortisol is associated with enhanced serotonin reuptake and reductions in serotonin levels as seen in animals and humans [330, 331] (Fig. 3). Stress-induced cortisol increases intestinal barrier dysfunction, as shown by crypt analyses sourced from both humans and rodents [332]. Moreover, administration of cortisol in a porcine model caused a shift in microbiota composition [333]. These studies suggest a role of cortisol in regulating both intestinal inflammation and microbiota composition.

Through inflammation-associated damage to CNS regions responsible for its inhibition or through hypersecretion of cortisol triggered by circulating immune factors, the HPA plays a significant role in intestinal inflammation, neuroinflammation and depression in IBD patients. Future studies should ask whether regions and neural pathways of the brain responsible for inhibition of the HPA axis are damaged or fail to function 
appropriately in animal models of IBD. Moreover, it would be interesting to ascertain whether there is evidence of GR downregulation due to hypersecretion of cortisol in these animals.

\section{Dysfunction of vagal nerve tone in IBD}

The vagus nerve $(\mathrm{VN})$, or cranial nerve $\mathrm{X}$, is a mixed parasympathetic nerve with $10-20 \%$ consisting of vagal efferent fibres and $80-90 \%$ afferent nerve fibres [334]. In the context of the GI tract, the VN's efferent fibres transmit information to the CNS about the mechanical distortion of the mucosa, luminal osmolarity, carbohydrate levels, bacterial products, neurotransmitters, the transformation of secondary bile acids, short-chain fatty acids, branched-chain amino acids, and gut hormones $[334,335]$. Sensory information travels to the nucleus tractus solitarius, located in the medulla oblongata [334, 335]. From there, nerve fibres project sensory information to different brain regions, including the ventrolateral medulla, amygdala, LC, thalamus, and hypothalamus [336]. Activation of the vagus afferent transmission can trigger the synthesis and release of the CRF by the PVN into the hypophysial-portal circulation, which then through downstream pathways discussed above, induce the release of glucocorticoids [334, 335].

Preganglionic neurons of vagal efferent fibres exit the brain from the medulla oblongata in the groove between the olive and the inferior cerebellar peduncle and in relation to the gut, innervate the muscular and mucosal layers of the gut both in the lamina propria and in the muscularis externa [334, 335]. Vagal afferent innervation of the intestines regulates the contraction of smooth muscles and glandular secretion [334, 335].

In IBD, VN tone dysfunction is suggested by vagus nerve stimulation (VNS) and functional studies. For instance, $\mathrm{VN}$ function was evaluated by a non-invasive test based on the heart reactions to deep breathing ( $E / I$ ratio) and tilt (acceleration and brake index). UC patients had a significantly lower $E / I$ ratio than controls, indicating vagal nerve dysfunction [337, 338]. Furthermore, VNS significantly improved the multivariate index of colitis in rats with TNBS-induced colitis [339] and chronic VNS in the same model improved colitis and decreased the production of pro-inflammatory cytokines (TNF- $\alpha$ and IL-6) [340]. In patients with CD, 12-month administration of VNS restored a homeostatic vagal tone and reduced the inflammatory state [341].

Studies have suggested that both the PFC and hippocampus hold modulatory roles of $\mathrm{VN}$ function [342, 343]. The PFC plays an indirect role in $\mathrm{VN}$ tone through its role in the regulation of anatomical centres involved in emotional and stress responses, such as the amygdala [293, 344]. Similarly, studies have indicated that the hippocampus is implicated in vagal functioning $[345,346,347]$. Electrical stimulation of the anterior hippocampus triggers depression of cardiovascular activation with cardiovascular responses requiring an intact PFC [345] Moreover, the anterior hippocampus has connections with anatomical areas regulating stress and emotions, including medial PFC, the amygdala and various subnuclei of the hypothalamus, including the anterior hypothalamus and lateral hypothalamus $[346,347,348]$.

The VN has been established to suppress intestinal inflammation via the cholinergic anti-inflammatory pathway $[279,349]$. This is believed to be mediated by the neurotransmitter-gated superfamily of ion channels, called $\alpha 7 \mathrm{nAChR}$, on macrophages [278, 279]. Stimulation of macrophage $\alpha 7 \mathrm{nAChR}$ results in the inhibition of LPSmediated activation of the NF- $\mathrm{kB}$ [350]. In macrophages, this effect is facilitated through the phosphorylation of Janus kinase 2 followed by activation of a STAT3 signalling pathway [278]. This causes direct inhibition of inflammatory cytokine production [278].

Upon activation, the $\mathrm{VN}$ releases $\mathrm{ACh}$ in the celiac mesenteric ganglia, which activates postsynaptic $\alpha 7 \mathrm{nAChR}$ on adrenergic neurons of the splenic nerve, leading to the release of noradrenaline (NA) in the spleen [351]. Adrenergic nerve fibres stimulate splenic memory $\mathrm{T}$ cells to synthesise $\mathrm{ACh}$ which can interact with $\alpha 7 \mathrm{nAChR}$ on adjacent macrophages [351]. In the intestines, the $\mathrm{VN}$ does not innervate directly resident macrophages but indirectly through nNOS-VIP-ACh interneurons projecting nerve endings in close proximity to resident macrophages and releasing $\mathrm{ACh}$ following appropriate stimulation [352].

Perhaps, neuroinflammation in brain areas implicated in the modulation of vagal tone is a contributing factor to VN dysfunction in IBD patients. Conversely, emotional and stress responses to the burden of IBD, genetics, or other unknown mechanisms may be at play. Future studies should investigate whether $\mathrm{VN}$ dysfunction seen in IBD patients may be triggered by neuroinflammation.

\section{Proposed treatment strategies}

Microglial activation and production of inflammatory mediators are believed to play pivotal roles in depression and anxiety noted in models of colitis $[126,135,136$, 140, 141, 247]. Microglia or the inflammatory mediators implicated in their activation may be therapeutic targets for treating depressive symptoms as well as intestinal inflammation in IBD patients. The microglial inhibitor minocycline, a tetracycline antibiotic, suppressed LPSstimulated inflammatory cytokine secretion and TLR expression as well as facilitating recovery from depressive behaviour and anhedonia in mice [353]. These findings were paralleled by a reduction in mRNA levels of IL-1 $\beta$, 
IL-6, and IDO in the hippocampus and cortex, which suggests improved neuronal functioning and prevention of neurodegeneration [353]. Importantly, treatment with minocycline inhibits IFN- $\alpha$ induced impairment of hippocampal neurogenesis by suppressing microglial activation [354]. Minocycline is believed to selectively suppress microglial M1 polarization by inhibiting transcription and nuclear translocation of NF-kB [355]. Minocycline treatment has also shown success in treating intestinal inflammation, it reduces macroscopic and microscopic damage in intestinal tissues of TNBS-treated mice [356]. However, to date, no research has explored the neuroinflammatory and behavioural impact of microglial inhibitors in animals with colitis, which may provide valuable insight into the role of microglia in depressive symptoms in IBD patients. As pro-inflammatory cytokines are capable of reducing serotonin bioavailability and hippocampal neurogenesis, targeting these cytokines may be therapeutically beneficial in the treatment of IBD-associated psychological impairments [211, 243]. TNF- $\alpha$ inhibitor, infliximab, significantly improved the disease state as well as psychological functioning in IBD patients [357]. However, TNF- $\alpha$ inhibitors are known to cause significant immunosuppression and may increase susceptibility to infections which may outweigh any benefits as an antidepressive treatment in these patients [358].

Antioxidants may offer a therapeutic advantage as ROS appear to be elevated in mice with colitis $[135,137]$. The antioxidant, salvianolic acid B (SalB), is shown to significantly affect microglia and expression of pro-inflammatory cytokines in the cortex and hippocampus [359, 360]. In mice exposed to chronic mild stress, SalB treatment did not induce morphological changes or expression levels of microglia in the hippocampus or cortex, but induced switching from microglial M1 polarization to M2 in the hippocampus and cortex [359]. Moreover, SalB aided in the recovery of impaired neurogenesis and volumetric decreases in the dentate gyrus and the granule cell layer [359]. Additionally, rats treated with SalB showed reduced NLRP3 inflammasome formation in the CA1 region of the hippocampus and restored autophagy function following the LPS challenge [360]. This suggests that SalB may promote autophagy clearance of excessive NLRP3 formation, suppressing the formation of NLRP3 pro-inflammatory cytokines such as IL-18 and IL-1 $\beta$ [360]. Within the intestines, SalB has been shown to improve intestinal barrier tight junction dysfunction in mice with IL-1 $\beta$-induced colitis [361].

Another promising therapeutic could be hydrogenrich water (HRW), a potent antioxidant, which can penetrate the cell membrane and selectively reduce hydroxide radicals and peroxynitrites without influencing physiological ROS [362, 363]. This has shown promising results in managing intestinal inflammation. Mice with DSS-induced colitis treated intraperitoneally with HRW showed reduced disease severity, pro-inflammatory cytokine production, and oxidative stress markers compared to untreated mice with DSSinduced colitis [364]. Importantly, mice given HRW and exposed to chronic unpredictable mild stress (CUMS) exhibit reduced ROS expression in the hippocampus and prefrontal cortex compared to mice exposed to CUMS without HRW [365]. Moreover, the HRW-treated group had significant reductions in IL-1 $\beta$ and inflammasome enzyme caspase- 1 in the hippocampus and cortex, and did not experience depressive symptoms compared to the untreated group following CUMS [365].

Given there has been evidence of reduced antioxidant GSH in mice with colitis, administration of GSH may offer therapeutic benefits for depressive symptoms [136]. This is assumed given that reduction in GSH has been noted in post-mortem PFC samples of patients with various psychiatric diseases such as MDD, schizophrenia, and bipolar disorder [147]. There appear to be limited studies exploring the therapeutic benefits of direct GSH treatment, however, the antioxidant precursor to GSH, $\mathrm{N}$-acetylcysteine, which can raise brain GSH levels, has shown some therapeutic success in treating depression [366]. GSH may also aid in treating intestinal inflammation as IBD mucosal samples show the deficiency of GSH and hypoactivity of the enzyme producing GSH, $\gamma$-glutamyl cysteine synthetase [367].

Expression of NOS in the hippocampus was paralleled with depressive symptoms observed in mice with colitis [136, 137]. Moreover, excessive production of NO by iNOS is noted in the inflamed gut of patients with IBD; inhibition of iNOS reduced the severity of intestinal inflammation in animal models of colitis [368, 369]. Therefore, targeting NOS with inhibitors may offer treatment for intestinal inflammation and depression. Promising results have been seen in mice with TNBS-induced colitis, in which administration of the NOS inhibitor $\mathrm{N}$-nitroarginine methyl ester resulted in an anti-depressant effect determined by reduced immobility time in the forced swim test [137].

Whilst no studies have shown COX upregulation in the brains of animals with colitis, it is known that inflammatory signalling can induce COX1 and 2 expression by microglia in rodent and human brains and correlates with neurodegenerative changes [370]. Hence, if they are present in the brains of IBD models, targeting COX enzymes may be a novel approach for the treatment of depression. This is premised on studies where patients receiving the COX-2 inhibitor, celecoxib, with the antidepressant sertraline or reboxetine had a greater improvement in 
depressive symptoms compared to the sertraline/reboxetine only group [371, 372].

\section{Conclusions}

This review aimed to describe the structural and physiological alterations in the GI tract, blood circulation, and the CNS in IBD patients and corresponding animal models of IBD in detail. The findings support the idea that CNS neuroinflammation is either a cause or contributor to the depression so often seen in IBD patients. Moreover, potential new neurobiological or intestinal targets for future studies have been revealed for the development of better therapeutic options for IBD-associated depression. Importantly, many underlying mechanisms of depression comorbid with IBD may be highly translatable to other systemic inflammatory diseases such as rheumatoid arthritis, obstructive pulmonary disease, and diabetes, which exhibit higher rates of depression compared to the general population.

\section{Abbreviations}

5-HT: 5-Hydroxytrptamine; Aß: Amyloid- $\beta$ peptide; AC: Anterior cingulate; Ach: Acetylcholine; AMPK: Adenosine monophosphate-activated protein kinase; ANS: Autonomic nervous system; AQP4: Aquaporin-4; BBB: Blood brain barrier; BCEC: Brain cerebral endothelial cells; BDNF: Brain-derived neurotrophic factor; CA1: Cornu ammonis; Caco: Colorectal adenocarcinoma; CBR: Cannabinoid receptor; CCL: Chemokine (C-C motif) ligand 2; CD: Crohn's disease; CNS: Central nervous system; COX: Cyclooxygenase; CRH: Corticotrophin releasing hormone; CSF: Cerebral spinal fluid; CUMS: Chronic unpredictable mild stress; CVO: Circumventricular organ; DSS: Dextran sulfate sodium; EC: Endothelial cell; EGC: Enteric glial cell; ENS: Enteric nervous system; FADD: Fas-associated protein with death domain; FITC: Fluorescein isothiocyanate; GABA: Gamma aminobutyric acid; GDNF: Glial cell line-derived neurotrophic factor; GFAP: Glial fibrillary acidic protein; GI: Gastrointestinal; GLU: Glutamate; GR: Glucocorticoid receptor; GSH: Glutathione; GSNO: Glial S-Nitrosoglutathione; HMGB1: High mobility group box protein 1; HRW: Hydrogen rich water; Iba-1: Ionized calcium-binding adapter molecule 1; IBD: Inflammatory bowel disease; IDO: Indoleamine-pyrrole 2,3-dioxygenase; IFN- $\gamma$ : Interferon gamma; Ig: Immunoglobulin; IL: Interleukin; iNOS: Inducible nitric oxide synthase; ISF: Brain interstitial fluid; JAM: Junction adhesion molecule; KAT: Kynurenine aminotransferase; KMO: Kynurenine 3-monooxygenase; KYN: Kynurenines; KYNA: Kynurenic acid; LC: Locus coeruleus; LH: Liver hydrolysate; LPS: Lipopolysaccharide; MDD: Major depressive disorder; MLC: Myosin light chain; MLCK: Myosin light chain kinase; MMP: Metalloproteinase; mRNA: Messenger ribonucleic acid; NE: Norepinephrine; NF-kB: Nuclear factor kappa-light-chain-enhancer of activated B cells; NLRP: Nucleotide-binding oligomerization domain; NO: Nitric oxide; NOS: Nitric oxide synthase; NPY: Neuropeptide Y; P: Phosphate; PFC: Prefrontal cortex; PGE2: Prostaglandin E2; PI3K: Phosphoinositide 3-kinase; PLD: Prelimbic division; QA: Quinolinic acid; ROCK: Rho-associated protein kinase; ROS: Reactive oxygen species; SHH: Sonic hedgehog; STAT3: Signal transducer and activator of transcription 3;T. muris: Trichuris muris; TEER:Transepithelial/ transendothelial electrical resistance; TGF- $\beta$ : Transforming growth factor beta; Th:T-helper; TJ: Tight junction; TLR: Toll-like receptor; TNBS: Trinitrobenzenesulfonic acid; TNF-a: Tumour necrosis factor alpha; TNFR: Tumour necrosis factor receptor; TRY: Tryptophan; UC: Ulcerative colitis; VIP: Vasoactive intestinal peptide; VN: Vagus nerve; VNS: Vagal nerve stimulation; WT: Wild type; ZO: Zonula occludens.
\end{abstract}

\section{Acknowledgements}

The authors would like to thank Victoria University and the Western Centre for Health Research and Education.

\section{Authors' contributions}

CFC: analysis of the literature, manuscript writing, preparation of figures and tables; RTF, RS, JCB, and VA: critical revision of the manuscript; JCB and KN: obtaining financial support; KN: conception and design, critical revision of the manuscript, and project administration. All authors read and approved the final manuscript.

\section{Funding}

CFC is funded by the College of Health and Biomedicine, Victoria University, Australia; RTF is funded by the Australian NHMRC Ideas grant GNT1158952 to $J C B$ and $K N ; V A, K N$, RTF received Research funding support from the Institute for Health and Sport, Victoria University, Australia.

\section{Availability of data and materials}

Not applicable.

\section{Declarations}

Ethics approval and consent to participate

Not applicable.

\section{Consent for publication}

Not applicable.

\section{Competing interests}

The authors declare that they have no competing interests.

\section{Author details}

${ }^{1}$ Institute for Heath and Sport, Victoria University, Western Centre for Health, Research and Education, Sunshine Hospital, Melbourne, VIC, Australia. ${ }^{2}$ Department of Pediatric Surgery, Pediatric Surgery Research Laboratories, Massachusetts General Hospital, Harvard Medical School, Boston, MA 02114, USA. ${ }^{3}$ Department of Anatomy and Physiology, The University of Melbourne, Melbourne, Australia. ${ }^{4}$ Immunology Program, Australian Institute of Musculoskeletal Science (AIMSS), Melbourne, VIC, Australia. ${ }^{5}$ Department of Medicine Western Health, Faculty of Medicine, Dentistry and Health Sciences, The University of Melbourne, Melbourne, VIC, Australia. ${ }^{6}$ Regenerative Medicine and Stem Cells Program, Australian Institute of Musculoskeletal Science (AIMSS), Melbourne, VIC, Australia. IInstitute for Health and Sport, Victoria University, Level 4 Research Labs, Western Centre for Health Research and Education, Sunshine Hospital, 176 Furlong Road, St Albans, VIC 3021, Australia.

Received: 5 July 2021 Accepted: 14 December 2021

Published online: 04 January 2022

\section{References}

1. Alatab S, Sepanlou SG, Ikuta K, Vahedi H, Bisignano C, Safiri S, et al. The global, regional, and national burden of inflammatory bowel disease in 195 countries and territories, 1990-2017: a systematic analysis for the Global Burden of Disease Study 2017. Lancet Gastroenterol Hepatol. 2020;5(1):17-30.

2. Byrne G, Rosenfeld G, Leung Y, Qian H, Raudzus J, Nunez C, et al. Prevalence of anxiety and depression in patients with inflammatory bowel disease. Can J Gastroenterol Hepatol. 2017;2017:6496727.

3. Nigro G, Angelini G, Grosso SB, Caula G, Sategna-Guidetti C. Psychiatric predictors of noncompliance in inflammatory bowel disease: psychiatry and compliance. J Clin Gastroenterol. 2001;32(1):1.

4. Katon WJ. Epidemiology and treatment of depression in patients with chronic medical illness. Dialogues Clin Neurosci. 2011;13(1):7-23.

5. Gracie DJ, Hamlin PJ, Ford AC. The influence of the brain-gut axis in inflammatory bowel disease and possible implications for treatment. Lancet Gastroenterol Hepatol. 2019;4(8):632-42.

6. Mikkelsen RL, Middelboe T, Pisinger C, Stage KB. Anxiety and depression in patients with chronic obstructive pulmonary disease (COPD). A review. Nordic J Psychiatry. 2004;58(1):65-70. 
7. Margaretten M, Julian L, Katz P, Yelin E. Depression in patients with rheumatoid arthritis: description, causes and mechanisms. Int J Clin Rheumtol. 2011;6(6):617-23.

8. Roy T, Lloyd CE. Epidemiology of depression and diabetes: a systematic review. J Affect Disord. 2012;142:S8-21.

9. Hendrickson BA, Gokhale R, Cho JH. Clinical aspects and pathophysiology of inflammatory bowel disease. Clin Microbiol Rev. 2002;15(1):79.

10. Zhang YZ, Li YY. Inflammatory bowel disease: pathogenesis. World J Gastroenterol. 2014:20(1):91-9.

11. Stavely R, Abalo R, Nurgali K. Targeting enteric neurons and plexitis for the management of inflammatory bowel disease. Curr Drug Targets. 2020;21(14):1428-39.

12. Rao M, Gershon MD. The bowel and beyond: the enteric nervous system in neurological disorders. Nat Rev Gastroenterol Hepatol. 2016;13(9):517-28.

13. Bernstein CN, Hitchon CA, Walld R, Bolton JM, Sareen J, Walker JR, et al. Increased burden of psychiatric disorders in inflammatory bowel disease. Inflamm Bowel Dis. 2019;25(2):360-8.

14. Mikocka-Walus A, Knowles SR, Keefer L, Graff L. Controversies revisited: a systematic review of the comorbidity of depression and anxiety with inflammatory bowel diseases. Inflamm Bowel Dis. 2016;22(3):752-62.

15. Walker JR, Ediger JP, Graff LA, Greenfeld JM, Clara I, Lix L, et al. The Manitoba IBD cohort study: a population-based study of the prevalence of lifetime and 12-month anxiety and mood disorders. Am J Gastroenterol. 2008;103(8):1989-97.

16. Troubat R, Barone P, Leman S, Desmidt T, Cressant A, Atanasova B, et al. Neuroinflammation and depression: a review. Eur J Neurosci. 2021;53(1):151-71.

17. Holsboer F. The corticosteroid receptor hypothesis of depression. Neuropsychopharmacology. 2000;23(5):477-501.

18. Sublette ME, Postolache TT. Neuroinflammation and depression: the role of indoleamine 2,3-dioxygenase (IDO) as a molecular pathway. Psychosom Med. 2012;74(7):668-72.

19. Eisch AJ, Petrik D. Depression and hippocampal neurogenesis: a road to remission? Science. 2012;338(6103):72-5

20. Dowlati Y, Herrmann N, Swardfager W, Liu H, Sham L, Reim EK, et al. A meta-analysis of cytokines in major depression. Biol Psychiatry. 2010;67(5):446-57.

21. Keefe B. Interferon-induced depression in hepatitis C: an update. Curr Psychiatry Rep. 2007;9(3):255-61.

22. Dantzer R, Kelley KW. Twenty years of research on cytokine-induced sickness behavior. Brain Behav Immun. 2007;21(2):153-60.

23. Raison C, Capuron L, Miller A. Cytokines sing the blues: inflammation and the pathogenesis of depression. Trends Immunol. 2006;27(1):24-31.

24. Zunszain P, Hepgul N, Pariante C. Inflammation and Depression. Behav Neurobiol Depression Treatment. 2012;14:135-51.

25. Brites D, Fernandes A. Neuroinflammation and depression: microglia activation, extracellular microvesicles and microRNA dysregulation. Front Cell Neurosci. 2015;9:476.

26. Zhang J, He H, Qiao Y, Zhou T, He H, Yi S, et al. Priming of microglia with IFN- $\gamma$ impairs adult hippocampal neurogenesis and leads to depression-like behaviors and cognitive defects. Glia. 2020;68(12):2674-92.

27. Kwidzinski E, Bechmann I. IDO expression in the brain: a double-edged sword. J Mol Med. 2007;85(12):1351-9.

28. McGuckin MA, Eri R, Simms LA, Florin TH, Radford-Smith G. Intestinal barrier dysfunction in inflammatory bowel diseases. Inflamm Bowel Dis. 2009:15(1):100-13.

29. Coskun M. Intestinal epithelium in inflammatory bowel disease. Front Med. 2014;1:24.

30. Jarret A, Jackson R, Duizer C, Healy ME, Zhao J, Rone JM, et al. Enteric nervous system-derived IL-18 orchestrates mucosal barrier immunity. Cell. 2020;180(1):50-63.e12.

31. Birchenough GMH, Johansson ME, Gustafsson JK, Bergström JH, Hansson GC. New developments in goblet cell mucus secretion and function. Mucosal Immunol. 2015;8(4):712-9.

32. Dorofeyev AE, Vasilenko IV, Rassokhina OA, Kondratiuk RB. Mucosal barrier in ulcerative colitis and Crohn's disease. Gastroenterol Res Pract. 2013;2013:431231.

33. Nakamura $Y$, Hamajima Y, Komori M, Yokota M, Suzuki M, Lin J. The role of atoh1 in mucous cell metaplasia. Int J Otolaryngol. 2012;212:438609.
34. Yang Q, Bermingham NA, Finegold MJ, Zoghbi HY. Requirement of Math 1 for secretory cell lineage commitment in the mouse intestine. Science. 2001;294(5549):2155-8.

35. Itoh H, Beck PL, Inoue N, Xavier R, Podolsky DK. A paradoxical reduction in susceptibility to colonic injury upon targeted transgenic ablation of goblet cells. J Clin Investig. 1999;104(11):1539-47.

36. Heazlewood CK, Cook MC, Eri R, Price GR, Tauro SB, Taupin D, et al. Aberrant mucin assembly in mice causes endoplasmic reticulum stress and spontaneous inflammation resembling ulcerative colitis. PLOS Med. 2008;5(3):e54

37. Van der Sluis M, De Koning BA, De Bruijn AC, Velcich A, Meijerink JP, Van Goudoever JB, et al. Muc2-deficient mice spontaneously develop colitis, indicating that MUC2 is critical for colonic protection. Gastroenterology. 2006:131(1):117-29.

38. Lee B, Moon KM, Kim CY. Tight junction in the intestinal epithelium: its association with diseases and regulation by phytochemicals. J Immunol Res. 2018;2018:2645465.

39. Landy J, Ronde E, English N, Clark SK, Hart AL, Knight SC, et al. Tight junctions in inflammatory bowel diseases and inflammatory bowel disease associated colorectal cancer. World J Gastroenterol. 2016;22(11):3117-26.

40. Garcia-Hernandez V, Quiros M, Nusrat A. Intestinal epithelial claudins: expression and regulation in homeostasis and inflammation. Ann NY Acad Sci. 2017:1397(1):66-79.

41. Oshima T, Miwa H, Joh T. Changes in the expression of claudins in active ulcerative colitis. J Gastroenterol Hepatol. 2008;23(s2):S146-50.

42. Prasad S, Mingrino R, Kaukinen K, Hayes KL, Powell RM, MacDonald TT, et al. Inflammatory processes have differential effects on claudins 2, 3 and 4 in colonic epithelial cells. Lab Invest. 2005;85(9):1139-62.

43. Weber CR, Nalle SC, Tretiakova M, Rubin DT, Turner JR. Claudin-1 and claudin-2 expression is elevated in inflammatory bowel disease and may contribute to early neoplastic transformation. Lab Invest. 2008:88(10):1110-20

44. Zeissig S, Bürgel N, Günzel D, Richter J, Mankertz J, Wahnschaffe U, et al. Changes in expression and distribution of claudin 2,5 and 8 lead to discontinuous tight junctions and barrier dysfunction in active Crohn's disease. Gut. 2007;56(1):61-72.

45. Poritz LS, Harris LR 3rd, Kelly AA, Koltun WA. Increase in the tight junction protein claudin-1 in intestinal inflammation. Dig Dis Sci. 2011;56(10):2802-9.

46. Guo G, Shi F, Zhu J, Shao Y, Gong W, Zhou G, et al. Piperine, a functional food alkaloid, exhibits inhibitory potential against TNBS-induced colitis via the inhibition of IKB- $\alpha / \mathrm{NF}-\mathrm{KB}$ and induces tight junction protein (claudin-1, occludin, and ZO-1) signaling pathway in experimental mice. Hum Exp Toxicol. 2019;39(4):477-91.

47. Li Q, Zhang $\mathrm{Q}$, Zhang $\mathrm{M}$, Wang $\mathrm{C}$, Zhu Z, Li N, et al. Effect of $\mathrm{n}-3$ polyunsaturated fatty acids on membrane microdomain localization of tight junction proteins in experimental colitis. FEBS J. 2008;275(3):411-20.

48. Yuan B, Zhou S, Lu Y, Liu J, Jin X, Wan H, et al. Changes in the expression and distribution of claudins, increased epithelial apoptosis, and a mannan-binding lectin-associated immune response lead to barrier dysfunction in dextran sodium sulfate-induced rat colitis. Gut Liver. 2015;9(6):734-40

49. Lu Y, Lin H, Zhang J, Wei J, Sun J, Han L. Sijunzi Decoction attenuates 2, 4, 6-trinitrobenzene sulfonic acid (TNBS)-induced colitis in rats and ameliorates TNBS-induced claudin-2 damage via NF-KB pathway in Caco2 cells. BMC Complement Altern Med. 2017;17(1):35.

50. Mao T, Li J, Liu L, Zhao W, Liu Y, Gao K, et al. Qingchang Wenzhong decoction attenuates DSS-induced colitis in rats by reducing inflammation and improving intestinal barrier function via upregulating the MSP/RON signalling pathway. Evid-Based Complem Altern Med. 2017:2017:4846876.

51. Cai L, Li X, Geng C, Lei X, Wang C. Molecular mechanisms of somatostatin-mediated intestinal epithelial barrier function restoration by upregulating claudin-4 in mice with DSS-induced colitis. Am J Physiol Cell Physiol. 2018;315(4):C527-36.

52. KucharzikT, Walsh SV, Chen J, Parkos CA, Nusrat A. Neutrophil transmigration in inflammatory bowel disease is associated with differential expression of epithelial intercellular junction proteins. Am J Pathol. 2001;159(6):2001-9. 
53. Wu D, Wu K, Zhu Q, Xiao W, Shan Q, Yan Z, et al. Formononetin administration ameliorates dextran sulfate sodium-induced acute colitis by inhibiting NLRP3 inflammasome signaling pathway. Mediators Inflamm. 2018;2018:3048532.

54. Scharl M, Paul G, Barrett KE, McCole DF. AMP-activated protein kinase mediates the interferon-gamma-induced decrease in intestinal epithelial barrier function. J Biol Chem. 2009;284(41):27952-63.

55. Das P, Goswami P, Das TK, Nag T, Sreenivas V, Ahuja V, et al. Comparative tight junction protein expressions in colonic Crohn's disease, ulcerative colitis, and tuberculosis: a new perspective. Virchows Arch. 2012;460(3):261-70.

56. Jin Y, Blikslager AT. The regulation of intestinal mucosal barrier by myosin light chain kinase/Rho kinases. Int J Mol Sci. 2020;21:10.

57. Blair SA, Kane SV, Clayburgh DR, Turner JR. Epithelial myosin light chain kinase expression and activity are upregulated in inflammatory bowel disease. Lab Invest. 2006;86(2):191-201.

58. Xu B, Li Y-L, Xu M, Yu C-C, Lian M-Q, Tang Z-Y, et al. Geniposide ameliorates TNBS-induced experimental colitis in rats via reducing inflammatory cytokine release and restoring impaired intestinal barrier function. Acta Pharmacol Sin. 2017;38(5):688-98.

59. Nighot P, Al-Sadi R, Rawat M, Guo S, Watterson DM, Ma T. Matrix metalloproteinase 9-induced increase in intestinal epithelial tight junction permeability contributes to the severity of experimental DSS colitis. Am J Physiol Gastrointest Liver Physiol. 2015;309(12):988-97.

60. Du J, Chen Y, Shi Y, Liu T, Cao Y, Tang Y, et al. 1,25-Dihydroxyvitamin D protects intestinal epithelial barrier by regulating the myosin light chain kinase signaling pathway. Inflamm Bowel Dis. 2015;21(11):2495-506.

61. Mankertz J, Tavalali S, Schmitz H, Mankertz A, Riecken EO, Fromm $\mathrm{M}$, et al. Expression from the human occludin promoter is affected by tumor necrosis factor alpha and interferon gamma. J Cell Sci. 2000;113(Pt 11):2085-90.

62. Cui W, Li LX, Sun CM, Wen Y, Zhou Y, Dong YL, et al. Tumor necrosis factor alpha increases epithelial barrier permeability by disrupting tight junctions in Caco-2 cells. Braz J Med Biol Res. 2010;43:330-7.

63. Vetrano S, Rescigno M, Cera MR, Correale C, Rumio C, Doni A, et al. Unique role of junctional adhesion molecule-a in maintaining mucosal homeostasis in inflammatory bowel disease. Gastroenterology. 2008;135(1):173-84.

64. Mandell KJ, Babbin BA, Nusrat A, Parkos CA. Junctional adhesion molecule 1 regulates epithelial cell morphology through effects on beta1 integrins and Rap1 activity. J Biol Chem. 2005;280(12):11665-74.

65. Ma TY, Iwamoto GK, Hoa NT, Akotia V, Pedram A, Boivin MA, et al. TNFa-induced increase in intestinal epithelial tight junction permeability requires NF-KB activation. Am J Physiol Gastrointest Liver Physiol. 2004;286(3):367-76

66. Segain J-P, Raingeard de la Blétière D, Sauzeau V, Bourreille A, Hilaret G, Cario-Toumaniantz C, et al. Rho kinase blockade prevents inflammation via nuclear factor kappa B inhibition: evidence in Crohn's disease and experimental colitis. Gastroenterology. 2003;124(5):1180-7.

67. Graham WV, Wang F, Clayburgh DR, Cheng JX, Yoon B, Wang Y, et al. Tumor necrosis factor-induced long myosin light chain kinase transcription is regulated by differentiation-dependent signaling events. J Biol Chem. 2006;281(36):26205-15.

68. Quiros M, Nusrat A. RhoGTPases, actomyosin signaling and regulation of the epithelial apical junctional complex. Semin Cell Dev Biol. 2014;36:194-203.

69. Bruewer M, Samarin S, Nusrat A. Inflammatory bowel disease and the apical junctional complex. Ann NY Acad Sci. 2006;1072(1):242-52.

70. Arnold TR, Stephenson RE, Miller AL. Rho GTPases and actomyosin: partners in regulating epithelial cell-cell junction structure and function. Exp Cell Res. 2017;358(1):20-30.

71. Al-Sadi R, Youssef M, Rawat M, Guo S, Dokladny K, Haque M, et al. MMP-9-induced increase in intestinal epithelial tight permeability is mediated by p38 kinase signaling pathway activation of MLCK gene. Am J Physiol Gastrointest Liver Physiol. 2018;316(2):278-90.

72. Ben David D, Reznick AZ, Srouji S, Livne E. Exposure to proinflammatory cytokines upregulates MMP-9 synthesis by mesenchymal stem cells-derived osteoprogenitors. Histochem Cell Biol. 2008;129(5):589-97.

73. O'Sullivan S, Gilmer JF, Medina C. Matrix metalloproteinases in inflammatory bowel disease: an update. Mediat Inflamm. 2015;215:964131.
74. Costa M, Brookes SJH, Hennig GW. Anatomy and physiology of the enteric nervous system. Gut. 2000;47(suppl 4):15.

75. Ochoa-Cortes F, Turco F, Linan-Rico A, Soghomonyan S, Whitaker E, Wehner $S$, et al. Enteric glial cells: a new frontier in neurogastroenterology and clinical target for inflammatory bowel diseases. Inflamm Bowel Dis. 2016;22(2):433-49.

76. Bernardazzi C, Pêgo B, de Souza HSP. Neuroimmunomodulation in the gut: focus on inflammatory bowel disease. Mediators Inflamm. 2016:2016:1363818.

77. Chow AK, Gulbransen BD. Potential roles of enteric glia in bridging neuroimmune communication in the gut. Am J Physiol Gastrointest Liver Physiol. 2016;312(2):145-52.

78. Zoppi S, Madrigal JLM, Pérez-Nievas BG, Marín-Jiménez I, Caso JR, Alou $\mathrm{L}$, et al. Endogenous cannabinoid system regulates intestinal barrier function in vivo through cannabinoid type 1 receptor activation. Am J Physiol Gastrointest Liver Physiol. 2011;302(5):565-71.

79. Neunlist M, Toumi F, Oreschkova T, Denis M, Leborgne J, Laboisse CL, et al. Human ENS regulates the intestinal epithelial barrier permeability and a tight junction-associated protein ZO-1 via VIPergic pathways. Am J Physiol Gastrointest Liver Physiol. 2003;285(5):G1028-36.

80. Chandrasekharan B, Jeppsson S, Pienkowski S, Belsham DD, Sitaraman SV, Merlin D, et al. Tumor necrosis factor-neuropeptide $Y$ cross talk regulates inflammation, epithelial barrier functions, and colonic motility. Inflamm Bowel Dis. 2013;19(12):2535-46.

81. Cheadle GA, Costantini TW, Bansal V, Eliceiri BP, Coimbra R. Cholinergic signaling in the gut: a novel mechanism of barrier protection through activation of enteric glia cells. Surg Infect (Larchmt). 2014;15(4):387-93.

82. Lesko S, Wessler I, Gäbel G, Petto C, Pfannkuche H. Cholinergic modulation of epithelial integrity in the proximal colon of pigs. Cells Tissues Organs. 2013;197(5):411-20.

83. Hons IM, Burda JE, Grider JR, Mawe GM, Sharkey KA. Alterations to enteric neural signaling underlie secretory abnormalities of the ileum in experimental colitis in the guinea pig. Am J Physiol Gastrointest Liver Physiol. 2009;296(4):G717-26.

84. Jayawardena D, Anbazhagan AN, Guzman G, Dudeja PK, Onyuksel H. Vasoactive intestinal peptide nanomedicine for the management of inflammatory bowel disease. Mol Pharm. 2017;14(11):3698-708.

85. Munro S, Thomas KL, Abu-Shaar M. Molecular characterization of a peripheral receptor for cannabinoids. Nature. 1993;365(6441):61-5.

86. Coutts AA, Irving AJ, Mackie K, Pertwee RG, Anavi-Goffer S. Localisation of cannabinoid $\mathrm{CB}(1)$ receptor immunoreactivity in the guinea pig and rat myenteric plexus. J Comp Neurol. 2002;448(4):410-22.

87. Banan A, Farhadi A, Fields JZ, Zhang LJ, Shaikh M, Keshavarzian A. The delta-isoform of protein kinase $C$ causes inducible nitric-oxide synthase and nitric oxide up-regulation: key mechanism for oxidant-induced carbonylation, nitration, and disassembly of the microtubule cytoskeleton and hyperpermeability of barrier of intestinal epithelia. J Pharmacol Exp Ther. 2003;305(2):482-94.

88. Han X, Fink MP, Yang R, Delude RL. Increased iNOS activity is essential for intestinal epithelial tight junction dysfunction in endotoxemic mice. Shock. 2004;21(3):261-70

89. Savidge TC, Newman P, Pothoulakis C, Ruhl A, Neunlist M, Bourreille $A$, et al. Enteric glia regulate intestinal barrier function and inflammation via release of S-nitrosoglutathione. Gastroenterology. 2007:132(4):1344-58.

90. Meir M, Flemming S, Burkard N, Bergauer L, Metzger M, Germer C-T, et al. Glial cell line-derived neurotrophic factor promotes barrier maturation and wound healing in intestinal epithelial cells in vitro. Am J Physiol Gastrointest Liver Physiol. 2015;309(8):613-24.

91. Cheadle GA, Costantini TW, Lopez N, Bansal V, Eliceiri BP, Coimbra R. Enteric glia cells attenuate cytomix-induced intestinal epithelial barrier breakdown. PLoS ONE. 2013;8(7):e69042.

92. Li Z, Zhang X, Zhou H, Liu W, Li J. Exogenous S-nitrosoglutathione attenuates inflammatory response and intestinal epithelial barrier injury in endotoxemic rats. J Trauma Acute Care Surg. 2016;80(6):977-84.

93. von Boyen GB, Steinkamp M, Geerling I, Reinshagen M, Schäfer KH, Adler G, et al. Proinflammatory cytokines induce neurotrophic factor expression in enteric glia: a key to the regulation of epithelial apoptosis in Crohn's disease. Inflamm Bowel Dis. 2006;12(5):346-54.

94. Xiao W, Wang W, Chen W, Sun L, Li X, Zhang C, et al. GDNF is involved in the barrier-inducing effect of enteric glial cells on intestinal epithelial 
cells under acute ischemia reperfusion stimulation. Mol Neurobiol. 2014;50(2):274-89.

95. Zhang DK, He FQ, Li TK, Pang XH, Cui DJ, Xie Q, et al. Glial-derived neurotrophic factor regulates intestinal epithelial barrier function and inflammation and is therapeutic for murine colitis. J Pathol. 2010;222(2):213-22.

96. Steinkamp M, Geerling I, Seufferlein T, von Boyen G, Egger B, Grossmann J, et al. Glial-derived neurotrophic factor regulates apoptosis in colonic epithelial cells. Gastroenterology. 2003:124(7):1748-57.

97. von Boyen GBT, Schulte N, Pflüger C, Spaniol U, Hartmann C, Steinkamp M. Distribution of enteric glia and GDNF during gut inflammation. BMC Gastroenterol. 2011;11(1):3.

98. Ramos GP, Papadakis KA. Mechanisms of disease: inflammatory bowel diseases. Mayo Clin Proc. 2019;94(1):155-65.

99. Lee SH, Kwon J, Cho M-L. Immunological pathogenesis of inflammatory bowel disease. Intest Res. 2018;16(1):26-42.

100. Choy MC, Visvanathan K, De Cruz P. An overview of the innate and adaptive immune system in inflammatory bowel disease. Inflamm Bowel Dis. 2017;23(1):2-13.

101. Guan Q. A comprehensive review and update on the pathogenesis of inflammatory bowel disease. J Immunol Res. 2019;2019:7247238.

102. Cibor D, Domagala-Rodacka R, Rodacki T, Jurczyszyn A, Mach T, Owczarek D. Endothelial dysfunction in inflammatory bowel diseases: pathogenesis, assessment and implications. World J Gastroenterol. 2016;22(3):1067-77.

103. Cromer WE, Mathis JM, Granger DN, Chaitanya GV, Alexander JS. Role of the endothelium in inflammatory bowel diseases. World J Gastroenterol. 2011;17(5):578-93.

104. Vijay-Kumar M, Aitken JD, Gewirtz AT. Toll like receptor-5: protecting the gut from enteric microbes. Semin Immunopathol. 2008;30(1):11-21.

105. Lodes MJ, Cong Y, Elson CO, Mohamath R, Landers CJ, Targan SR, et al. Bacterial flagellin is a dominant antigen in Crohn disease. J Clin Investig. 2004;113(9):1296-306.

106. Del Zotto B, Mumolo G, Pronio AM, Montesani C, Tersigni R, Boirivant M. TGF-beta1 production in inflammatory bowel disease: differing produc tion patterns in Crohn's disease and ulcerative colitis. Clin Exp Immunol. 2003;134(1):120-6.

107. Babyatsky MW, Rossiter G, Podolsky DK. Expression of transforming growth factors alpha and beta in colonic mucosa in inflammatory bowel disease. Gastroenterology. 1996;110(4):975-84.

108. Yun S-M, Kim S-H, Kim E-H. The molecular mechanism of transforming growth factor- $\beta$ signaling for intestinal fibrosis: a mini-review. Front Pharmacol. 2019;10:162.

109. Antonov AS, Antonova GN, Fujii M, ten Dijke P, Handa V, Catravas JD, et al. Regulation of endothelial barrier function by TGF- $\beta$ type I receptor ALK5: potential role of contractile mechanisms and heat shock protein 90. J Cell Physiol. 2012;227(2):759-71.

110. van Meeteren LA, ten Dijke P. Regulation of endothelial cell plasticity by TGF-B. Cell Tissue Res. 2012;347(1):177-86.

111. Correa I, Veny M, Esteller M, Piqué JM, Yagüe J, Panés J, et al. Defective IL-10 production in severe phenotypes of Crohn's disease. J Leukoc Biol. 2009:85(5):896-903.

112. Oshima T, Laroux FS, Coe LL, Morise Z, Kawachi S, Bauer P, et al. Interferon- $\gamma$ and Interleukin-10 reciprocally regulate endothelial junction integrity and barrier function. Microvasc Res. 2001;61(1):130-43.

113. Curciarello R, Sobande T, Jones S, Giuffrida P, Sabatino AD, Docena G, et al. Human neutrophil elastase proteolytic activity in ulcerative colitis favors the loss of function of therapeutic monoclonal antibodies. J Inflamm Res. 2020;13:1-7.

114. Tatsuki M, Hatori R, Nakazawa T, Ishige T, Hara T, Kagimoto S, et al. Serological cytokine signature in paediatric patients with inflammatory bowel disease impacts diagnosis. Sci Rep. 2020;10(1):14638.

115. Korolkova OY, Myers JN, Pellom ST, Wang L, M'Koma AE. Characterization of serum cytokine profile in predominantly colonic inflammatory bowel disease to delineate ulcerative and Crohn's colitides. Clin Med Insights. 2015;8:612

116. Pastor Rojo O, López San Román A, Albéniz Arbizu E, de la Hera Martínez A, Ripoll Sevillano E, Albillos Martínez A. Serum lipopolysaccharide-binding protein in endotoxemic patients with inflammatory bowel disease. Inflamm Bowel Dis. 2007;13(3):269-77.
117. Guo Y, Zhou G, He C, Yang W, He Z, Liu Z. Serum levels of lipopolysaccharide and 1,3- $\beta$-D-glucan refer to the severity in patients with Crohn's disease. Mediat Inflamm. 2015;215:843089.

118. Jaffer U, Wade RG, Gourlay T. Cytokines in the systemic inflammatory response syndrome: a review. HSR Proc Intensive Care Cardiovasc Anesth. 2010;2(3):161-75.

119. Banks WA. Blood-brain barrier transport of cytokines: a mechanism for neuropathology. Curr Pharm Des. 2005;1 1(8):973-84.

120. Cohen SS, Min M, Cummings EE, Chen X, Sadowska GB, Sharma S, et al. Effects of interleukin- 6 on the expression of tight junction proteins in isolated cerebral microvessels from yearling and adult sheep. NeurolmmunoModulation. 2013:20(5):264-73.

121. Lv S, Song H-L, Zhou Y, Li L-X, Cui W, Wang W, et al. Tumour necrosis factor-a affects blood-brain barrier permeability and tight junctionassociated occludin in acute liver failure. Liver Int. 2010;30(8):1198-210.

122. Rochfort KD, Collins LE, Murphy RP, Cummins PM. Downregulation of blood-brain barrier phenotype by proinflammatory cytokines involves NADPH oxidase-dependent ROS generation: consequences for interendothelial adherens and tight junctions. PLOS ONE. 2014;9(7):e101815.

123. Wang $Y$, Jin $S$, Sonobe $Y$, Cheng $Y$, Horiuchi $H$, Parajuli $B$, et al. Interleukin-1 $\beta$ induces blood-brain barrier disruption by downregulating sonic hedgehog in astrocytes. PLOS ONE. 2014;9(10):e110024.

124. Lin R, Chen F, Wen S, Teng T, Pan Y, Huang H. Interleukin-10 attenuates impairment of the blood-brain barrier in a severe acute pancreatitis rat model. J Inflamm (Lond). 2018;15:4.

125. Sonobe Y, Takeuchi H, Kataoka K, Li H, Jin S, Mimuro M, et al. Interleukin-25 expressed by brain capillary endothelial cells maintains bloodbrain barrier function in a protein kinase Cepsilon-dependent manner. J Biol Chem. 2009:284(46):31834-42.

126. Han Y, Zhao T, Cheng X, Zhao M, Gong S-H, Zhao Y-Q, et al. Cortical inflammation is increased in a DSS-induced colitis mouse model. Neurosci Bull. 2018;34(6):1058-66.

127. Hathaway CA, Appleyard CB, Percy WH, Williams JL. Experimental colitis increases blood-brain barrier permeability in rabbits. Am J Physiol Gastrointest Liver Physiol. 1999:276(5):1174-80.

128. Natah SS, Mouihate A, Pittman QJ, Sharkey KA. Disruption of the blood-brain barrier during TNBS colitis. Neurogastroenterol Motil. 2005:17(3):433-46.

129. Barnes SE, Zera KA, Ivison GT, Buckwalter MS, Engleman EG. Brain profiling in murine colitis and human epilepsy reveals neutrophils and TNFa as mediators of neuronal hyperexcitability. J Neuroinflammation. 2021:18(1):199.

130. Weihong P, Abba JK. Interactions of cytokines with the blood-brain barrier: implications for feeding. Curr Pharm Des. 2003;9(10):827-34.

131. Chavan SS, Pavlov VA, Tracey KJ. Mechanisms and therapeutic relevance of neuro-immune communication. Immunity. 2017;46(6):927-42.

132. Browning KN, Verheijden S, Boeckxstaens GE. The vagus nerve in appetite regulation, mood, and intestinal inflammation. Gastroenterology. 2017;152(4):730-44

133. Dantzer R, O'Connor JC, Freund GG, Johnson RW, Kelley KW. From inflammation to sickness and depression: when the immune system subjugates the brain. Nat Rev Neurosci. 2008;9(1):46-56.

134. Shaftel SS, Carlson TJ, Olschowka JA, Kyrkanides S, Matousek SB, O'Banion MK. Chronic interleukin-1 $\beta$ expression in mouse brain leads to leukocyte infiltration and neutrophil-independent blood-brain barrier permeability without overt neurodegeneration. J Neurosci. 2007:27(35):9301-9

135. Zonis S, Pechnick RN, Ljubimov VA, Mahgerefteh M, Wawrowsky K, Michelsen KS, et al. Chronic intestinal inflammation alters hippocampal neurogenesis. J Neuroinflammation. 2015;12(1):65.

136. Haj-Mirzaian A, Amiri S, Amini-Khoei H, Hosseini M-J, Haj-Mirzaian A, Momeny $\mathrm{M}$, et al. Anxiety- and depressive-like behaviors are associated with altered hippocampal energy and inflammatory status in a mouse model of Crohn's disease. Neuroscience. 2017:366:124-37.

137. Heydarpour P, Rahimian R, Fakhfouri G, Khoshkish S, Fakhraei N, SalehiSadaghiani M, et al. Behavioral despair associated with a mouse model of Crohn's disease: role of nitric oxide pathway. Prog Neuropsychopharmacol Biol Psychiatry. 2016;64:131-41.

138. Talley S, Valiauga R, Anderson L, Cannon AR, Choudhry MA, Campbell EM. DSS-induced inflammation in the colon drives a proinflammatory signature in the brain that is ameliorated by prophylactic treatment 
with the S100A9 inhibitor paquinimod. J Neuroinflammation. 2021;18(1):263.

139. He X-f, Li L-I, Xian W-b, Li M-y, Zhang L-y, Xu J-h, et al. Chronic colitis exacerbates NLRP3-dependent neuroinflammation and cognitive impairment in middle-aged brain. J Neuroinflammation. 2021;18(1):153.

140. Salvo E, Stokes P, Keogh CE, Brust-Mascher I, Hennessey C, Knotts TA, et al. A murine model of pediatric inflammatory bowel disease causes microbiota-gut-brain axis deficits in adulthood. Am J Physiol Gastrointest Liver Physiol. 2020;319(3):G361-74.

141. Han Y, Ding L, Cheng X, Zhao M, Zhao T, Guo L, et al. Hypoxia augments cerebral inflammation in a dextran sulfate sodium-induced colitis mouse model. Front Cell Neurosci. 2020;14(433):611764.

142. Riazi K, Galic MA, Kentner AC, Reid AY, Sharkey KA, Pittman QJ. Microglia-dependent alteration of glutamatergic synaptic transmission and plasticity in the hippocampus during peripheral inflammation. J Neurosci. 2015;35(12):4942-52.

143. Riazi K, Galic MA, Kuzmiski JB, Ho W, Sharkey KA, Pittman QJ. Microglial activation and TNFalpha production mediate altered CNS excitability following peripheral inflammation. Proc Natl Acad Sci USA. 2008;105(44):17151-6.

144. Wang K, Yuan CP, Wang W, Yang ZQ, Cui W, Mu LZ, et al. Expression of interleukin 6 in brain and colon of rats with TNBS-induced colitis. World J Gastroenterol. 2010;16(18):2252-9.

145. Hovatta I, Juhila J, Donner J. Oxidative stress in anxiety and comorbid disorders. Neurosci Res. 2010;68(4):261-75.

146. Rezin GT, Amboni G, Zugno Al, Quevedo J, Streck EL. Mitochondrial dysfunction and psychiatric disorders. Neurochem Res. 2008;34(6):1021.

147. Gawryluk JW, Wang J-F, Andreazza AC, Shao L, Young LT. Decreased levels of glutathione, the major brain antioxidant, in post-mortem prefrontal cortex from patients with psychiatric disorders. Int J Neuropsychopharmacol. 2011:14(1):123-30.

148. Alex P, Zachos NC, Nguyen T, Gonzales L, Chen T-E, Conklin LS, et al. Distinct cytokine patterns identified from multiplex profiles of murine DSS and TNBS-induced colitis. Inflamm Bowel Dis. 2009;15(3):341-52.

149. Dhir A, Kulkarni SK. Nitric oxide and major depression. Nitric Oxide. 2011;24(3):125-31.

150. Wegener $G$, Volke V, Rosenberg R. Endogenous nitric oxide decreases hippocampal levels of serotonin and dopamine in vivo. Br J Pharmacol. 2000;130(3):575-80

151. Calabrese V, Mancuso C, Calvani M, Rizzarelli E, Butterfield DA, Giuffrida Stella AM. Nitric oxide in the central nervous system: neuroprotection versus neurotoxicity. Nat Rev Neurosci. 2007;8(10):766-75.

152. Wang S, Song R, Wang Z, Jing Z, Wang S, Ma J. S100A8/A9 in inflammation. Front Immunol. 2018;9:1298.

153. Corbin BD, Seeley EH, Raab A, Feldmann J, Miller MR, Torres VJ, et al. Metal chelation and inhibition of bacterial growth in tissue abscesses. Science. 2008;319(5865):962-5.

154. Sunahori K, Yamamura M, Yamana J, Takasugi K, Kawashima M, Yamamoto $\mathrm{H}$, et al. The S100A8/A9 heterodimer amplifies proinflammatory cytokine production by macrophages via activation of nuclear factor kappa B and p38 mitogen-activated protein kinase in rheumatoid arthritis. Arthritis Res Ther. 2006;8(3):R69.

155. Altwegg LA, Neidhart M, Hersberger M, Müller S, Eberli FR, Corti R, et al. Myeloid-related protein 8/14 complex is released by monocytes and granulocytes at the site of coronary occlusion: a novel, early, and sensitive marker of acute coronary syndromes. Eur Heart J. 2007;28(8):941-8.

156. Austermann J, Zenker S, Roth J. S100-alarmins: potential therapeutic targets for arthritis. Expert Opin Ther Targets. 2017;21(7):739-51.

157. Bogumil T, Rieckmann P, Kubuschok B, Felgenhauer K, Brück W. Serum levels of macrophage-derived protein MRP-8/14 are elevated in active multiple sclerosis. Neurosci Lett. 1998;247(2-3):195-7.

158. Frosch M, Vogl T, Waldherr R, Sorg C, Sunderkötter C, Roth J. Expression of MRP 8 and MRP 14 by macrophages is a marker for severe forms of glomerulonephritis. J Leukoc Biol. 2004;75(2):198-206.

159. Bjarnason I. The use of fecal calprotectin in inflammatory bowel disease. Gastroenterol Hepatol (N Y). 2017;13(1):53-6.

160. Yan L, Bjork P, Butuc R, Gawdzik J, Earley J, Kim G, et al. Beneficial effects of quinoline-3-carboxamide (ABR-215757) on atherosclerotic plaque morphology in S100A12 transgenic ApoE null mice. Atherosclerosis. 2013;228(1):69-79.
161. Björk P, Björk A, VoglT, Stenström M, Liberg D, Olsson A, et al. Identification of human $\$ 100 A 9$ as a novel target for treatment of autoimmune disease via binding to quinoline-3-carboxamides. PLoS Biol. 2009;7(4):e97.

162. Stankiewicz AM, Goscik J, Majewska A, Swiergiel AH, Juszczak GR. The effect of acute and chronic social stress on the hippocampal transcriptome in mice. PLoS ONE. 2015;10(11):e0142195.

163. Guo H, Callaway JB, Ting JPY. Inflammasomes: mechanism of action, role in disease, and therapeutics. Nat Med. 2015;21(7):677-87.

164. Song L, Pei L, Yao S, WU Y, Shang Y. NLRP3 inflammasome in neurological diseases, from functions to therapies. Front Cell Neurosci. 2017;11:63.

165. Iliff JJ, Wang M, Liao Y, Plogg BA, Peng W, Gundersen GA, et al. A paravascular pathway facilitates CSF flow through the brain parenchyma and the clearance of interstitial solutes, including amyloid \& \#x3b2. Sci Transl Med. 2012;4(147):14711.

166. Da Mesquita S, Louveau A, Vaccari A, Smirnov I, Cornelison RC, Kingsmore KM, et al. Functional aspects of meningeal lymphatics in ageing and Alzheimer's disease. Nature. 2018;560(7717):185-91.

167. Rasmussen MK, Mestre H, Nedergaard M. The glymphatic pathway in neurological disorders. Lancet Neurol. 2018;17(11):1016-24.

168. Verheggen ICM, Van Boxtel MPJ, Verhey FRJ, Jansen JFA, Backes WH. Interaction between blood-brain barrier and glymphatic system in solute clearance. Neurosci Biobehav Rev. 2018;90:26-33.

169. Kinney JW, Bemiller SM, Murtishaw AS, Leisgang AM, Salazar AM, Lamb BT. Inflammation as a central mechanism in Alzheimer's disease. Alzheimers Dement (N Y). 2018:4:575-90.

170. Matsuoka Y, Picciano M, Malester B, LaFrancois J, Zehr C, Daeschner JM, et al. Inflammatory responses to amyloidosis in a transgenic mouse model of Alzheimer's disease. Am J Pathol. 2001;158(4):1345-54.

171. Gold M, El Khoury J. $\beta$-amyloid, microglia, and the inflammasome in Alzheimer's disease. Semin Immunopathol. 2015;37(6):607-11.

172. Schläger C, Körner H, Krueger M, Vidoli S, Haberl M, Mielke D, et al. Effector T-cell trafficking between the leptomeninges and the cerebrospinal fluid. Nature. 2016;530(7590):349-53.

173. Streit WJ, Mrak RE, Griffin WST. Microglia and neuroinflammation: a pathological perspective. J Neuroinflammation. 2004;1 (1):14.

174. Ginhoux F, Lim S, Hoeffel G, Low D, Huber T. Origin and differentiation of microglia. Frontiers in Cellular Neuroscience. 2013;7(45).

175. Wake $\mathrm{H}$, Fields RD. Physiological function of microglia. Neuron Glia Biol. 2011;7(1):1-3.

176. Brás JP, Bravo J, Freitas J, Barbosa MA, Santos SG, Summavielle T, et al. TNF-alpha-induced microglia activation requires miR-342: impact on NF-kB signaling and neurotoxicity. Cell Death Dis. 2020;11(6):415.

177. Kaushik DK, Thounaojam MC, Kumawat KL, Gupta M, Basu A. Interleukin-1 $\beta$ orchestrates underlying inflammatory responses in microglia via Krüppel-like factor 4. J Neurochem. 2013;127(2):233-44.

178. Capuco A, Urits I, Hasoon J, Chun R, Gerald B, Wang JK, et al. Current perspectives on gut microbiome dysbiosis and depression. Adv Ther. 2020;37(4):1328-46.

179. Krady JK, Lin H-W, Liberto CM, Basu A, Kremlev SG, Levison SW. Ciliary neurotrophic factor and interleukin-6 differentially activate microglia. J Neurosci Res. 2008;86(7):1538-47.

180. Reynolds MR, Berry RW, Binder LI. Nitration in neurodegeneration: deciphering the "Hows" "nYs." Biochemistry. 2007:46(25):7325-36.

181. Swanson KV, Deng M, Ting JPY. The NLRP3 inflammasome: molecular activation and regulation to therapeutics. Nat Rev Immunol. 2019:19(8):477-89.

182. Fitzpatrick FA. Cyclooxygenase enzymes: regulation and function. Curr Pharm Des. 2004;10(6):577-88.

183. Qin L, Wu X, Block ML, Liu Y, Breese GR, Hong JS, et al. Systemic LPS causes chronic neuroinflammation and progressive neurodegeneration. Glia. 2007;55(5):453-62.

184. Hanlon LA, Huh JW, Raghupathi R. Minocycline transiently reduces microglia/macrophage activation but exacerbates cognitive deficits following repetitive traumatic brain injury in the neonatal rat. J Neuropathol Exp Neurol. 2016;75(3):214-26.

185. Fukumoto K, Takagi N, Yamamoto R, Moriyama Y, Takeo S, Tanonaka K. Prostanoid EP1 receptor antagonist reduces blood-brain barrier leakage after cerebral ischemia. Eur J Pharmacol. 2010;640(1-3):82-6. 
186. Ikeda-Matsuo Y, Tanji H, Narumiya S, Sasaki Y. Inhibition of prostaglandin E2 EP3 receptors improves stroke injury via anti-inflammatory and antiapoptotic mechanisms. J Neuroimmunol. 2011;238(1-2):34-43.

187. Frankowski JC, DeMars KM, Ahmad AS, Hawkins KE, Yang C, Leclerc JL, et al. Detrimental role of the EP1 prostanoid receptor in blood-brain barrier damage following experimental ischemic stroke. Sci Rep. 2015;5(1):17956

188. Liang X, Lin L, Woodling NS, Wang Q, Anacker C, Pan T, et al. Signaling via the prostaglandin $E_{2}$ receptor EP4 exerts neuronal and vascular protection in a mouse model of cerebral ischemia. J Clin Invest. 2011;121(11):4362-71.

189. DeMars KM, McCrea AO, Siwarski DM, Sanz BD, Yang C, Candelario-Jali E. Protective effects of L-902,688, a prostanoid EP4 receptor agonist, against acute blood-brain barrier damage in experimental ischemic stroke. Front Neurosci. 2018;12:89.

190. Guillot FL, Audus KL. Angiotensin peptide regulation of fluid-phase endocytosis in brain microvessel endothelial cell monolayers. J Cereb Blood Flow Metab. 1990;10(6):827-34.

191. Minami T, Okazaki J, Kawabata A, Kawaki H, Okazaki Y, Tohno Y. Roles of nitric oxide and prostaglandins in the increased permeability of the blood-brain barrier caused by lipopolysaccharide. Environ Toxicol Pharmacol. 1998;5(1):35-41.

192. Xaio H, Banks WA, Niehoff ML, Morley JE. Effect of LPS on the permeability of the blood-brain barrier to insulin. Brain Res. 2001:896(1-2):36-42.

193. Griffin ÉW, Skelly DT, Murray CL, Cunningham C. Cyclooxygenase1-dependent prostaglandins mediate susceptibility to systemic inflammation-induced acute cognitive dysfunction. J Neurosci. 2013;33(38):15248-58

194. Hassan AM, Jain P, Reichmann F, Mayerhofer R, Farzi A, Schuligoi R, et al. Repeated predictable stress causes resilience against colitis-induced behavioral changes in mice. Front Behav Neurosci. 2014:8:386.

195. Cazareth J, Guyon A, Heurteaux C, Chabry J, Petit-Paitel A. Molecular and cellular neuroinflammatory status of mouse brain after systemic lipopolysaccharide challenge: importance of CCR2/CCL2 signaling. J Neuroinflammation. 2014;11:132.

196. Banisadr G, Quéraud-Lesaux F, Boutterin MC, Pélaprat D, Zalc B, Rostène $W$, et al. Distribution, cellular localization and functional role of CCR2 chemokine receptors in adult rat brain. J Neurochem. 2002;81(2):257-69.

197. Curzytek K, Leśkiewicz M. Targeting the CCL2-CCR2 axis in depressive disorders. Pharmacol Rep. 2021;73(4):1052-62.

198. Charo IF, Myers SJ, Herman A, Franci C, Connolly AJ, Coughlin SR Molecular cloning and functional expression of two monocyte chemoattractant protein 1 receptors reveals alternative splicing of the carboxyl-terminal tails. Proc Natl Acad Sci USA. 1994;91(7):2752-6.

199. El Khoury J, Toft M, Hickman SE, Means TK, Terada K, Geula C, et al. Ccr2 deficiency impairs microglial accumulation and accelerates progression of Alzheimer-like disease. Nat Med. 2007;13(4):432-8.

200. DeCarolis NA, Eisch AJ. Hippocampal neurogenesis as a target for the treatment of mental illness: a critical evaluation. Neuropharmacology. 2010;58(6):884-93.

201. Bremner JD, Narayan M, Anderson ER, Staib LH, Miller HL, Charney DS. Hippocampal volume reduction in major depression. Am J Psychiatry. 2000;157(1):115-8.

202. Stockmeier CA, Mahajan GJ, Konick LC, Overholser JC, Jurjus GJ, Meltzer $\mathrm{HY}$, et al. Cellular changes in the postmortem hippocampus in major depression. Biol Psychiatry. 2004;56(9):640-50.

203. Toda T, Parylak SL, Linker SB, Gage FH. The role of adult hippocampal neurogenesis in brain health and disease. Mol Psychiatry. 2019:24(1):67-87.

204. Aarum J, Sandberg K, Haeberlein SLB, Persson MAA. Migration and differentiation of neural precursor cells can be directed by microglia. Proc Natl Acad Sci. 2003;100(26):15983.

205. Kreisel T, Wolf B, Keshet E, Licht T. Unique role for dentate gyrus microglia in neuroblast survival and in VEGF-induced activation. Glia. 2019:67(4):594-618.

206. Sierra A, Encinas JM, Deudero JJP, Chancey JH, Enikolopov G, Overstreet-Wadiche LS, et al. Microglia shape adult hippocampal neurogenesis through apoptosis-coupled phagocytosis. Cell Stem Cell. 2010;7(4):483-95
207. Chen L-M, Bao C-H, Wu Y, Liang S-H, Wang D, Wu L-Y, et al. Tryptophan-kynurenine metabolism: a link between the gut and brain for depression in inflammatory bowel disease. J Neuroinflammation. 2021;18(1):135

208. Sherr CJ, Roberts JM. CDK inhibitors: positive and negative regulators of G1-phase progression. Genes Dev. 1999;13(12):1501-12.

209. Pechnick RN, Zonis S, Wawrowsky K, Pourmorady J, Chesnokova V. p21Cip1 restricts neuronal proliferation in the subgranular zone of the dentate gyrus of the hippocampus. Proc Natl Acad Sci USA. 2008;105(4):1358-63.

210. Zonis S, Ljubimov VA, Mahgerefteh M, Pechnick RN, Wawrowsky K, Chesnokova V. p21Cip restrains hippocampal neurogenesis and protects neuronal progenitors from apoptosis during acute systemic inflammation. Hippocampus. 2013;23(12):1383-94.

211. Cacci E, Claasen JH, Kokaia Z. Microglia-derived tumor necrosis factoralpha exaggerates death of newborn hippocampal progenitor cells in vitro. J Neurosci Res. 2005;80(6):789-97.

212. Iosif RE, Ekdahl CT Ahlenius H, Pronk CJH, Bonde S, Kokaia Z, et al. Tumor necrosis factor receptor 1 is a negative regulator of progenitor proliferation in adult hippocampal neurogenesis. J Neurosci. 2006;26(38):9703.

213. Wajant $H$, Siegmund D. TNFR1 and TNFR2 in the Control of the Life and Death Balance of Macrophages. Frontiers in Cell and Developmental Biology. 2019;7(91)

214. Wang X, Fu S, Wang Y, Yu P, Hu J, Gu W, et al. Interleukin-1 beta mediates proliferation and differentiation of multipotent neural precursor cells through the activation of SAPK/JNK pathway. Mol Cell Neurosci. 2007;36(3):343-54.

215. Koo JW, Duman RS. IL-1 beta is an essential mediator of the antineurogenic and anhedonic effects of stress. Proc Natl Acad Sci USA. 2008:105(2):751-6.

216. Koo JW, Duman RS. IL-1 $\beta$ is an essential mediator of the antineurogenic and anhedonic effects of stress. Proc Natl Acad Sci. 2008;105(2):751.

217. Goshen I, Kreisel T, Ben-Menachem-Zidon O, Licht T, Weidenfeld J, Ben-Hur T, et al. Brain interleukin-1 mediates chronic stress-induced depression in mice via adrenocortical activation and hippocampal neurogenesis suppression. Mol Psychiatry. 2008;13(7):717-28.

218. Barrientos RM, Sprunger DB, Campeau S, Higgins EA, Watkins LR, Rudy $J W$, et al. Brain-derived neurotrophic factor mRNA downregulation produced by social isolation is blocked by intrahippocampal interleukin-1 receptor antagonist. Neuroscience. 2003;121(4):847-53.

219. Arrigoni E, Greene RW. Schaffer collateral and perforant path inputs activate different subtypes of NMDA receptors on the same CA1 pyramidal cell. Br J Pharmacol. 2004;142(2):317-22.

220. Stellwagen D, Beattie EC, Seo JY, Malenka RC. Differential regulation of AMPA receptor and GABA receptor trafficking by tumor necrosis factoralpha. J Neurosci. 2005;25(12):3219-28.

221. Stellwagen D, Malenka RC. Synaptic scaling mediated by glial TNFalpha. Nature. 2006;440(7087):1054-9.

222. Dong X-x, Wang Y, Qin Z-h. Molecular mechanisms of excitotoxicity and their relevance to pathogenesis of neurodegenerative diseases. Acta pharmacologica Sinica. 2009;30(4):379-87.

223. Van Damme P, Bogaert E, Dewil M, Hersmus N, Kiraly D, Scheveneels $W$, et al. Astrocytes regulate GluR2 expression in motor neurons and their vulnerability to excitotoxicity. Proc Natl Acad Sci USA. 2007:104(37):14825-30.

224. Bell JD, Park E, Ai J, Baker AJ. PICK1-mediated GluR2 endocytosis contributes to cellular injury after neuronal trauma. Cell Death Differ. 2009;16(12):1665-80.

225. Foster AC, Whetsell WO Jr, Bird ED, Schwarcz R. Quinolinic acid phosphoribosyltransferase in human and rat brain: activity in Huntington's disease and in quinolinate-lesioned rat striatum. Brain Res. 1985;336(2):207-14

226. Odaira T, Nakagawasai O, Takahashi K, Nemoto W, Sakuma W, Lin J-R, et al. Mechanisms underpinning AMP-activated protein kinase-related effects on behavior and hippocampal neurogenesis in an animal model of depression. Neuropharmacology. 2019;150:121-33.

227. Peixoto CA, Oliveira WHd, Araújo SMdR, Nunes AKS. AMPK activation: Role in the signaling pathways of neuroinflammation and neurodegeneration. Experimental Neurology. 2017:298:31-41. 
228. Nakagawasai O, Yamada K, Odaira T, Takahashi K, Nemoto W, Sakuma W, et al. Liver hydrolysate improves depressive-like behavior in olfactory bulbectomized mice: Involvement of hippocampal neurogenesis through the AMPK/BDNF/CREB pathway. J Pharmacol Sci. 2020;143(1):52-5.

229. Nakagawasai O, Yamada K, Takahashi K, Odaira T, Sakuma W, Ishizawa D, et al. Liver hydrolysate prevents depressive-like behavior in an animal model of colitis: Involvement of hippocampal neurogenesis via the AMPK/BDNF pathway. Behavioural Brain Research. 2020;390:112640.

230. Thomas JO, Travers AA. HMG1 and 2, and 'architectural' DNA-binding proteins. Trends Biochem Sci. 2001;26(3):167-74.

231. Paudel YN, Shaikh MF, Chakraborti A, Kumari Y, Aledo-Serrano Á, Aleksovska K, et al. HMGB1: A Common Biomarker and Potential Target for TBI, Neuroinflammation, Epilepsy, and Cognitive Dysfunction. Frontiers in Neuroscience. 2018;12(628)

232. Hei Y, Chen R, Yi X, Long Q, Gao D, Liu W. HMGB1 Neutralization attenuates hippocampal neuronal death and cognitive impairment in rats with chronic cerebral hypoperfusion via suppressing inflammatory responses and oxidative stress. Neuroscience. 2018;383:150-9.

233. Mazarati A, Maroso M, lori V, Vezzani A, Carli M. High-mobility group box-1 impairs memory in mice through both toll-like receptor 4 and receptor for advanced glycation end products. Exp Neurol. 2011;232(2):143-8.

234. Sasaki T, Liu K, Agari T, Yasuhara T, Morimoto J, Okazaki M, et al. Antihigh mobility group box 1 antibody exerts neuroprotection in a rat model of Parkinson's disease. Exp Neurol. 2016;275:220-31.

235. Andrews PW, Bharwani A, Lee KR, Fox M, Thomson JA. Is serotonin an upper or a downer? The evolution of the serotonergic system and its role in depression and the antidepressant response. Neurosci Biobehav Rev. 2015;51:164-88.

236. Baumeister AA, Hawkins MF, Uzelac SM. The myth of reserpine-induced depression: role in the historical development of the monoamine hypothesis. J Hist Neurosci. 2003;12(2):207-20.

237. Rutter JJ, Auerbach SB. Acute uptake inhibition increases extracellular serotonin in the rat forebrain. J Pharmacol Exp Ther. 1993;265(3):1319-24.

238. Bymaster FP, Zhang W, Carter PA, Shaw J, Chernet E, Phebus L, et al. Fluoxetine, but not other selective serotonin uptake inhibitors, increases norepinephrine and dopamine extracellular levels in prefrontal cortex. Psychopharmacology. 2002;160(4):353-61.

239. Oswald I, Brezinova V, Dunleavy DLF. On the slowness of action of tricyclic antidepressant drugs. Br J Psychiatry. 1972;120(559):673-7.

240. Ruhé HG, Mason NS, Schene AH. Mood is indirectly related to serotonin, norepinephrine and dopamine levels in humans: a meta-analysis of monoamine depletion studies. Mol Psychiatry. 2007;12(4):331-59.

241. Jacobs BL, van Praag H, Gage FH. Adult brain neurogenesis and psychiatry: a novel theory of depression. Mol Psychiatry. 2000;5(3):262-9.

242. Guillemin GJ, Smythe G, Takikawa O, Brew BJ. Expression of indoleamine 2,3-dioxygenase and production of quinolinic acid by human microglia, astrocytes, and neurons. Glia. 2005;49(1):15-23.

243. Oxenkrug GF. Tryptophan kynurenine metabolism as a common mediator of genetic and environmental impacts in major depressive disorder: the serotonin hypothesis revisited 40 years later. Isr J Psychiatry Relat Sci. 2010;47(1):56-63.

244. Schwarcz R, Bruno JP, Muchowski PJ, Wu H-Q. Kynurenines in the mammalian brain: when physiology meets pathology. Nat Rev Neurosci. 2012;13(7):465-77.

245. Tavares RG, Tasca Cl, Santos CE, Alves LB, Porciúncula LO, Emanuelli $T$, et al. Quinolinic acid stimulates synaptosomal glutamate release and inhibits glutamate uptake into astrocytes. Neurochem Int. 2002;40(7):621-7.

246. Lugo-Huitrón R, Ugalde Muñiz P, Pineda B, Pedraza-Chaverrí J, Ríos C, Pérez-de la Cruz V. Quinolinic acid: an endogenous neurotoxin with multiple targets. Oxid Med Cell Longev. 2013;2013:104024.

247. Bercik P, Verdu EF, Foster JA, Macri J, Potter M, Huang X, et al. Chronic gastrointestinal inflammation induces anxiety-like behavior and alters central nervous system biochemistry in mice. Gastroenterology. 2010;139(6):2102-12.e1.

248. Shiomi Y, Nishiumi S, Ooi M, Hatano N, Shinohara M, Yoshie T, et al. GCMS-based metabolomic study in mice with colitis induced by dextran sulfate sodium. Inflamm Bowel Dis. 2011;17(11):2261-74.
249. Gurtner GJ, Newberry RD, Schloemann SR, McDonald KG, Stenson WF. Inhibition of indoleamine 2,3-dioxygenase augments trinitrobenzene sulfonic acid colitis in mice. Gastroenterology. 2003;125(6):1762-73.

250. Sroor HM, Hassan AM, Zenz G, Valadez-Cosmes P, Farzi A, Holzer P, et al. Experimental colitis reduces microglial cell activation in the mouse brain without affecting microglial cell numbers. Sci Rep. 2019;9(1):20217.

251. Wolf AM, Wolf D, Rumpold H, Moschen AR, Kaser A, Obrist P, et al. Overexpression of indoleamine 2,3-dioxygenase in human inflammatory bowel disease. Clin Immunol. 2004;113(1):47-55.

252. Ghia JE, Li N, Wang H, Collins M, Deng Y, El-Sharkawy RT, et al. Serotonin Has a Key Role in Pathogenesis of Experimental Colitis. Gastroenterology. 2009;137(5):1649-60.

253. van der Velden VH. Glucocorticoids: mechanisms of action and anti-inflammatory potential in asthma. Mediators Inflamm. 1998;7(4):229-37.

254. Herman JP, McKlveen JM, Ghosal S, Kopp B, Wulsin A, Makinson R, et al. Regulation of the hypothalamic-pituitary-adrenocortical stress response. Compr Physiol. 2016;6(2):603-21.

255. Vale W, Spiess J, Rivier C, Rivier J. Characterization of a 41-residue ovine hypothalamic peptide that stimulates secretion of corticotropin and beta-endorphin. Science. 1981;213(4514):1394-7.

256. Rivier C, Vale W. Modulation of stress-induced ACTH release by corticotropin-releasing factor, catecholamines and vasopressin. Nature. 1983;305(5932):325-7.

257. Smith SM, Vale WW. The role of the hypothalamic-pituitary-adrenal axis in neuroendocrine responses to stress. Dialogues Clin Neurosci. 2006;8(4):383-95.

258. Charmandari E, Tsigos C, Chrousos G. Endocrinology of the stress response. Annu Rev Physiol. 2005;67:259-84.

259. Watkins LR, Goehler LE, Relton JK, Tartaglia N, Silbert L, Martin D, et al. Blockade of interleukin-1 induced hyperthermia by subdiaphragmatic vagotomy: evidence for vagal mediation of immune-brain communication. Neurosci Lett. 1995;183(1):27-31.

260. Ching S, Zhang H, Belevych N, He L, Lai W, Pu X-a, et al. EndothelialSpecific Knockdown of Interleukin-1 (IL-1) Type 1 Receptor Differentially Alters CNS Responses to IL-1 Depending on Its Route of Administration. The Journal of Neuroscience. 2007;27(39):10476.

261. Elander L, Engström L, Ruud J, Mackerlova L, Jakobsson P-J, Engblom $D$, et al. Inducible prostaglandin E2 synthesis interacts in a temporally supplementary sequence with constitutive prostaglandin-synthesizing enzymes in creating the hypothalamic-pituitary-adrenal axis response to immune challenge. J Neurosci. 2009;29(5):1404.

262. Capuron L, Miller AH. Immune system to brain signaling: neuropsychopharmacological implications. Pharmacol Ther. 2011;130(2):226-38.

263. Rogatsky I, Logan SK, Garabedian MJ. Antagonism of glucocorticoid receptor transcriptional activation by the $\mathrm{c}$-Jun $\mathrm{N}$-terminal kinase. Proc Natl Acad Sci. 1998;95(5):2050.

264. Wang $X$, Wu H, Miller AH. Interleukin 1a (IL-1a) induced activation of p38 mitogen-activated protein kinase inhibits glucocorticoid receptor function. Mol Psychiatry. 2004;9(1):65-75.

265. Pariante CM, Pearce BD, Pisell TL, Sanchez CI, Po C, Su C, et al. The proinflammatory cytokine, interleukin-1a, reduces glucocorticoid receptor translocation and function1. Endocrinology. 1999;140(9):4359-66.

266. McKay LI, Cidlowski JA. Molecular control of immune/inflammatory responses: interactions between nuclear factor-kb and steroid receptor-signaling pathways. Endocr Rev. 1999;20(4):435-59.

267. Steensberg A, Fischer CP, Keller C, Møller K, Pedersen BK. IL-6 enhances plasma IL-1 ra, IL-10, and cortisol in humans. Am J Physiol Endocrinol Metab. 2003;285(2):E433-7.

268. Straub RH, Vogl D, Gross V, Lang B, Schölmerich J, Andus T. Association of humoral markers of inflammation and dehydroepiandrosterone sulfate or cortisol serum levels in patients with chronic inflammatory bowel disease. Am J Gastroenterol. 1998;93(11):2197-202.

269. Fries E, Dettenborn L, Kirschbaum C. The cortisol awakening response (CAR): facts and future directions. Int J Psychophysiol. 2009;72(1):67-73.

270. Atreya R, Neurath MF. Involvement of IL-6 in the pathogenesis of inflammatory bowel disease and colon cancer. Clin Rev Allergy Immunol. 2005;28(3):187-96. 
271. Mudter J, Neurath MF. II-6 signaling in inflammatory bowel disease: pathophysiological role and clinical relevance. Inflamm Bowel Dis. 2007;13(8):1016-23.

272. Luo $\mathrm{C}$, Zhang $\mathrm{H}$. The role of proinflammatory pathways in the pathogenesis of colitis-associated colorectal cancer. Mediat Inflamm. 2017;2017:5126048.

273. Pellissier S, Dantzer C, Mondillon L, Trocme C, Gauchez A-S, Ducros V, et al. Relationship between vagal tone, cortisol, TNF-alpha, epinephrine and negative affects in Crohn's disease and irritable bowel syndrome. PLOS ONE. 2014;9(9):e105328.

274. Straub RH, Herfarth H, Falk W, Andus T, Schölmerich J. Uncoupling of the sympathetic nervous system and the hypothalamic-pituitary-adrenal axis in inflammatory bowel disease? J Neuroimmunol. 2002;126(1):116-25

275. Reichmann F, Hassan AM, Farzi A, Jain P, Schuligoi R, Holzer P. Dextran sulfate sodium-induced colitis alters stress-associated behaviour and neuropeptide gene expression in the amygdala-hippocampus network of mice. Sci Rep. 2015;5:9970.

276. Holzer P, Farzi A, Hassan AM, Zenz G, Jačan A, Reichmann F. Visceral inflammation and immune activation stress the brain. Front Immunol. 2017:8:1613.

277. Deng QJ, Deng DJ, Che J, Zhao HR, Yu JJ, Lu YY. Hypothalamic paraventricular nucleus stimulation reduces intestinal injury in rats with ulcerative colitis. World J Gastroenterol. 2016;22(14):3769-76.

278. de Jonge WJ, van der Zanden EP, The FO, Bijlsma MF, van Westerloo DJ, Bennink RJ, et al. Stimulation of the vagus nerve attenuates macrophage activation by activating the Jak2-STAT3 signaling pathway. Nat Immunol. 2005;6(8):844-51.

279. Goverse G, Stakenborg M, Matteoli G. The intestinal cholinergic antiinflammatory pathway. J Physiol. 2016;594(20):5771-80.

280. Poe GR, Foote S, Eschenko O, Johansen JP, Bouret S, Aston-Jones G, et al. Locus coeruleus: a new look at the blue spot. Nat Rev Neurosci. 2020;21(11):644-59.

281. Itoi K, Jiang YQ, Iwasaki Y, Watson SJ. Regulatory mechanisms of corticotropin-releasing hormone and vasopressin gene expression in the hypothalamus. J Neuroendocrinol. 2004;16(4):348-55.

282. Ma S, Morilak DA. Chronic intermittent cold stress sensitises the hypothalamic-pituitary-adrenal response to a novel acute stress by enhancing noradrenergic influence in the rat paraventricular nucleus. J Neuroendocrinol. 2005;17(11):761-9.

283. Reyes BA, Valentino RJ, Xu G, Van Bockstaele EJ. Hypothalamic projections to locus coeruleus neurons in rat brain. Eur J Neurosci. 2005;22(1):93-106.

284. Jedema HP, Grace AA. Corticotropin-releasing hormone directly activates noradrenergic neurons of the locus ceruleus recorded in vitro. J Neurosci. 2004;24(43):9703-13.

285. Reyes BA, Valentino RJ, Van Bockstaele EJ. Stress-induced intracellular trafficking of corticotropin-releasing factor receptors in rat locus coeruleus neurons. Endocrinology. 2008;149(1):122-30.

286. Valentino RJ, Van Bockstaele E. Convergent regulation of locus coeruleus activity as an adaptive response to stress. Eur J Pharmacol. 2008;583(2-3):194-203.

287. Dunn AJ, Swiergiel AH. The role of corticotropin-releasing factor and noradrenaline in stress-related responses, and the inter-relationships between the two systems. Eur J Pharmacol. 2008;583(2-3):186-93.

288. Ziegler DR, Cass WA, Herman JP. Excitatory influence of the locus coeruleus in hypothalamic-pituitary-adrenocortical axis responses to stress. J Neuroendocrinol. 1999;11(5):361-9.

289. Roy HA, Green AL. The central autonomic network and regulation of bladder function. Front Neurosci. 2019;13(535).

290. Benarroch EE. The central autonomic network: functional organization, dysfunction, and perspective. Mayo Clin Proc. 1993;68(10):988-1001.

291. Ulrich-Lai YM, Herman JP. Neural regulation of endocrine and autonomic stress responses. Nat Rev Neurosci. 2009;10(6):397-409.

292. Gianaros PJ, Van Der Veen FM, Jennings JR. Regional cerebral blood flow correlates with heart period and high-frequency heart period variability during working-memory tasks: Implications for the cortical and subcortical regulation of cardiac autonomic activity. Psychophysiology. 2004:41(4):521-30.

293. Thayer JF, Sternberg E. Beyond Heart Rate Variability. Ann N Y Acad Sci. 2006:1088(1):361-72.
294. Jankord R, Herman JP. Limbic regulation of hypothalamo-pituitaryadrenocortical function during acute and chronic stress. Ann N Y Acad Sci. 2008:1148:64-73.

295. Figueiredo HF, Bodie BL, Tauchi M, Dolgas CM, Herman JP. Stress integration after acute and chronic predator stress: differential activation of central stress circuitry and sensitization of the hypothalamo-pituitaryadrenocortical axis. Endocrinology. 2003;144(12):5249-58.

296. Figueiredo HF, Bruestle A, Bodie B, Dolgas CM, Herman JP. The medial prefrontal cortex differentially regulates stress-induced c-fos expression in the forebrain depending on type of stressor. Eur J Neurosci. 2003;18(8):2357-64

297. Diorio D, Viau V, Meaney MJ. The role of the medial prefrontal cortex (cingulate gyrus) in the regulation of hypothalamic-pituitary-adrenal responses to stress. J Neurosci. 1993;13(9):3839-47.

298. Sullivan RM, Gratton A. Lateralized Effects of Medial Prefrontal Cortex Lesions on Neuroendocrine and Autonomic Stress Responses in Rats. J Neurosci. 1999;19(7):2834

299. Ahima RS, Harlan RE. Charting of type II glucocorticoid receptor-like immunoreactivity in the rat central nervous system. Neuroscience. 1990:39(3):579-604

300. Akana SF, Chu A, Soriano L, Dallman MF. Corticosterone exerts sitespecific and state-dependent effects in prefrontal cortex and amygdala on regulation of adrenocorticotropic hormone, insulin and fat depots. J Neuroendocrinol. 2001;13(7):625-37

301. Herman JP, Cullinan WE. Neurocircuitry of stress: central control of the hypothalamo-pituitary-adrenocortical axis. Trends Neurosci. 1997:20(2):78-84

302. Jacobson L, Sapolsky R. The role of the hippocampus in feedback regulation of the hypothalamic-pituitary-adrenocortical axis. Endocr Rev. 1991;12(2):118-34.

303. Dunn JD, Orr SE. Differential plasma corticosterone responses to hippocampal stimulation. Exp Brain Res. 1984;54(1):1-6.

304. Rubin RT, Mandell AJ, Crandall PH. Corticosteroid responses to limbic stimulation in man: localization of stimulus sites. Science. 1966;153(3737):767-8.

305. Fendler K, Karmos G, Telegdy G. The effect of hippocampal lesion on pituitary-adrenal function. Acta Physiol Acad Sci Hung. 1961;20:293-7.

306. Knigge KM. Adrenocortical response to stress in rats with lesions in hippocampus and amygdala. Proc Soc Exp Biol Med. 1961;108:18-21.

307. Knigge KM, Hays M. Evidence of Inhibitive Role of Hippocampus in Neural Regulation of ACTH Release. Proc Soc Exp Biol Med. 1963:114:67-9.

308. Sapolsky RM, Krey LC, McEwen BS. Glucocorticoid-sensitive hippocampal neurons are involved in terminating the adrenocortical stress response. Proc Natl Acad Sci U S A. 1984;81(19):6174-7.

309. Herman JP, Cullinan WE, Morano MI, Akil H, Watson SJ. Contribution of the ventral subiculum to inhibitory regulation of the hypothalamopituitary-adrenocortical axis. J Neuroendocrinol. 1995;7(6):475-82.

310. Feldman S, Weidenfeld J. The dorsal hippocampus modifies the negative feedback effect of glucocorticoids on the adrenocortical and median eminence CRF-41 responses to photic stimulation. Brain Res. 1993;614(1):227-32

311. Marrie RA, Walld R, Bolton JM, Sareen J, Walker JR, Patten SB, et al. Physical comorbidities increase the risk of psychiatric comorbidity in immune-mediated inflammatory disease. Gen Hosp Psychiatry. 2018;51:71-8.

312. Sun Y, Li L, Xie R, Wang B, Jiang K, Cao H. Stress Triggers Flare of Inflammatory Bowel Disease in Children and Adults. Frontiers in Pediatrics. 2019;7(432).

313. Walker JR, Ediger JP, Graff LA, Greenfeld JM, Clara I, Lix L, et al. The Manitoba IBD Cohort Study: A Population-Based Study of the Prevalence of Lifetime and 12-Month Anxiety and Mood Disorders. Official journal of the American College of Gastroenterology | ACG. 2008;103(8).

314. Bernstein CN, Singh S, Graff LA, Walker JR, Miller N, Cheang M. A Prospective Population-Based Study of Triggers of Symptomatic Flares in IBD. Official journal of the American College of Gastroenterology | ACG. 2010;105(9).

315. Larauche $M$, Kiank C, Tache Y. Corticotropin releasing factor signaling in colon and ileum: regulation by stress and pathophysiological implications. J Physiol Pharmacol. 2009;60 Suppl 7(Suppl 7):33-46. 
316. Tache Y, Larauche M, Yuan P-Q, Million M. Brain and Gut CRF Signaling: Biological Actions and Role in the Gastrointestinal Tract. Curr Mol Pharmacol. 2018;11(1):51-71.

317. Hill LT, Kidson SH, Michell WL. Corticotropin-releasing factor: A possible key to gut dysfunction in the critically ill. Nutrition. 2013;29(7):948-52.

318. Söderholm JD, Yang PC, Ceponis P, Vohra A, Riddell R, Sherman PM, et al. Chronic stress induces mast cell-dependent bacterial adherence and initiates mucosal inflammation in rat intestine. Gastroenterology. 2002;123(4):1099-108.

319. Zheng PY, Feng BS, Oluwole C, Struiksma S, Chen X, Li P, et al. Psychological stress induces eosinophils to produce corticotrophin releasing hormone in the intestine. Gut. 2009:58(11):1473.

320. Amsterdam A, Tajima K, Sasson R. Cell-specific regulation of apoptosis by glucocorticoids: implication to their anti-inflammatory action. Biochem Pharmacol. 2002;64(5-6):843-50.

321. Reichlin S. Neuroendocrine-immune interactions. N Engl J Med. 1993;329(17):1246-53.

322. Franchimont D, Kino T, Galon J, Meduri GU, Chrousos G. Glucocorticoids and inflammation revisited: the state of the art. $\mathrm{NIH}$ clinical staff conference Neuroimmunomodulation. 2002;10(5):247-60.

323. Lee A, De Mei C, Fereira M, Marotta R, Yoon HY, Kim K, et al. Dexamethasone-loaded Polymeric Nanoconstructs for Monitoring and Treating Inflammatory Bowel Disease. Theranostics. 2017;7(15):3653-66.

324. Busillo JM, Azzam KM, Cidlowski JA. Glucocorticoids Sensitize the Innate Immune System through Regulation of the NLRP3 Inflammasome. J Biol Chem. 2011;286(44):38703-13.

325. Chinenov Y, Rogatsky I. Glucocorticoids and the innate immune system: Crosstalk with the Toll-like receptor signaling network. Mol Cell Endocrinol. 2007;275(1):30-42.

326. Ding Y, Gao Z-G, Jacobson KA, Suffredini AF. Dexamethasone Enhances ATP-Induced Inflammatory Responses in Endothelial Cells. J Pharmacol Exp Ther. 2010;335(3):693.

327. Yu IT, Lee S-H, Lee Y-S, Son H. Differential effects of corticosterone and dexamethasone on hippocampal neurogenesis in vitro. Biochem Biophys Res Commun. 2004:317(2):484-90

328. Agasse F, Mendez-David I, Christaller W, Carpentier R, Braz BY, David DJ, et al. Chronic Corticosterone Elevation Suppresses Adult Hippocampal Neurogenesis by Hyperphosphorylating Huntingtin. Cell Reports. 2020;32(1).

329. Rubin RT. Adrenal Cortical Activity Changes in Manic-Depressive IIIness: Influence on Intermediary Metabolism of Tryptophan. Arch Gen Psychiatry. 1967;17(6):671-9.

330. Tafet GE, Toister-Achituv M, Shinitzky M. Enhancement of serotonin uptake by cortisol: a possible link between stress and depression. Cogn Affect Behav Neurosci. 2001;1 (1):96-104

331. Tafet GE, Idoyaga-Vargas VP, Abulafia DP, Calandria JM, Roffman SS, Chiovetta A, et al. Correlation between cortisol level and serotonin uptake in patients with chronic stress and depression. Cogn Affect Behav Neurosci. 2001;1(4):388-93.

332. Zheng G, Victor Fon G, Meixner W, Creekmore A, Zong Y, M KD, et al. Chronic stress and intestinal barrier dysfunction: Glucocorticoid receptor and transcription repressor HES1 regulate tight junction protein Claudin-1 promoter. Sci Rep. 2017:7(1):4502.

333. Petrosus E, Silva EB, Lay D Jr, Eicher SD. Effects of orally administered cortisol and norepinephrine on weanling piglet gut microbial populations and Salmonella passage. J Anim Sci. 2018;96(11):4543-51.

334. Breit S, Kupferberg A, Rogler G, Hasler G. Vagus Nerve as Modulator of the Brain-Gut Axis in Psychiatric and Inflammatory Disorders. Frontiers in Psychiatry. 2018;9(44)

335. Zhao L, Xiong Q, Stary CM, Mahgoub OK, Ye Y, Gu L, et al. Bidirectional gut-brain-microbiota axis as a potential link between inflammatory bowel disease and ischemic stroke. J Neuroinflammation. 2018;15(1):339.

336. Berthoud H-R, Neuhuber WL. Functional and chemical anatomy of the afferent vagal system. Auton Neurosci. 2000;85(1):1-17.

337. Bonaz B, Sinniger V, Pellissier S. The Vagus Nerve in the Neuro-Immune Axis: Implications in the Pathology of the Gastrointestinal Tract. Frontiers in immunology. 2017:8:1452-

338. Lindgren S, Stewenius J, Sjölund K, Lilja B, Sundkvist G. Autonomic vagal nerve dysfunction in patients with ulcerative colitis. Scand J Gastroenterol. 1993;28(7):638-42.
339. Meregnani J, Clarençon D, Vivier M, Peinnequin A, Mouret C, Sinniger V, et al. Anti-inflammatory effect of vagus nerve stimulation in a rat model of inflammatory bowel disease. Auton Neurosci. 2011;160(1-2):82-9.

340. Sun P, Zhou K, Wang S, Li P, Chen S, Lin G, et al. Involvement of MAPK NF-KB Signaling in the Activation of the Cholinergic Anti-Inflammatory Pathway in Experimental Colitis by Chronic Vagus Nerve Stimulation. PLOS ONE. 2013;8(8):e69424.

341. Sinniger V, Pellissier S, Fauvelle F, Trocmé C, Hoffmann D, Vercueil L, et al. A 12-month pilot study outcomes of vagus nerve stimulation in Crohn's disease. Neurogastroenterology \& Motility. 2020;32(10):e13911.

342. Colzato LS, Jongkees BJ, de Wit M, van der Molen MJW, Steenbergen L. Variable heart rate and a flexible mind: Higher resting-state heart rate variability predicts better task-switching. Cogn Affect Behav Neurosci. 2018;18(4):730-8

343. Bonaz B, Sinniger V, Pellissier S. Vagal tone: effects on sensitivity, motility, and inflammation. Neurogastroenterol Motil. 2016;28(4):455-62.

344. Liu W-Z, Zhang W-H, Zheng Z-H, Zou J-X, Liu X-X, Huang S-H, et al. Identification of a prefrontal cortex-to-amygdala pathway for chronic stress-induced anxiety. Nat Commun. 2020;1 1(1):2221.

345. Ruit KG, Neafsey EJ. Hippocampal input to a "visceral motor" corticobulbar pathway: an anatomical and electrophysiological study in the rat. Exp Brain Res. 1990;82(3):606-16.

346. Blessing EM, Beissner F, Schumann A, Brünner F, Bär KJ. A data-driven approach to mapping cortical and subcortical intrinsic functional connectivity along the longitudinal hippocampal axis. Hum Brain Mapp. 2016;37(2):462-76.

347. Tannenholz L, Jimenez JC, Kheirbek MA. Local and regional heterogeneity underlying hippocampal modulation of cognition and mood. Front Behav Neurosci. 2014;8:147.

348. Scott BG, Weems CF. Resting vagal tone and vagal response to stress: associations with anxiety, aggression, and perceived anxiety control among youths. Psychophysiology. 2014;51(8):718-27.

349. Martelli D, McKinley MJ, McAllen RM. The cholinergic anti-inflammatory pathway: a critical review. Auton Neurosci. 2014;182:65-9.

350. Wang H, Liao H, Ochani M, Justiniani M, Lin X, Yang L, et al. Cholinergic agonists inhibit HMGB1 release and improve survival in experimental sepsis. Nat Med. 2004;10(11):1216-21.

351. Rosas-Ballina M, Olofsson PS, Ochani M, Valdés-Ferrer SI, Levine YA, Reardon C, et al. Acetylcholine-synthesizing T cells relay neural signals in a vagus nerve circuit. Science. 2011;334(6052):98-101.

352. Cailotto C, Gomez-Pinilla PJ, Costes LM, van der Vliet J, Di Giovangiulio $M$, Némethova A, et al. Neuro-anatomical evidence indicating indirect modulation of macrophages by vagal efferents in the intestine but not in the spleen. PLoS One. 2014;9(1):e87785.

353. Henry CJ, Huang Y, Wynne A, Hanke M, Himler J, Bailey MT, et al. Minocycline attenuates lipopolysaccharide (LPS)-induced neuroinflammation, sickness behavior, and anhedonia. J Neuroinflammation. 2008:5(1):15.

354. Zheng LS, Kaneko N, Sawamoto K. Minocycline treatment ameliorates interferon-alpha- induced neurogenic defects and depression-like behaviors in mice. Front Cell Neurosci. 2015;9:5.

355. Kobayashi K, Imagama S, Ohgomori T, Hirano K, Uchimura K, Sakamoto $\mathrm{K}$, et al. Minocycline selectively inhibits M1 polarization of microglia. Cell Death \& Disease. 2013;4(3):e525-e.

356. Garrido-Mesa N, Camuesco D, Arribas B, Comalada M, Bailón E, CuetoSola $\mathrm{M}$, et al. The intestinal anti-inflammatory effect of minocycline in experimental colitis involves both its immunomodulatory and antimicrobial properties. Pharmacol Res. 2011;63(4):308-19.

357. Lichtenstein GR, Bala M, Han C, DeWoody K, Schaible T. Infliximab Improves Quality of Life in Patients with Crohn's Disease. Inflamm Bowel Dis. 2002;8(4):237-43.

358. Her M, Kavanaugh A. Alterations in immune function with biologic therapies for autoimmune disease. Journal of Allergy and Clinical Immunology. 2016;137(1):19-27.

359. Zhang J-q, Wu X-h, Feng Y, Xie X-f, Fan Y-h, Yan S, et al. Salvianolic acid $B$ ameliorates depressive-like behaviors in chronic mild stress-treated mice: involvement of the neuroinflammatory pathway. Acta Pharmacologica Sinica. 2016;37(9):1141-53.

360. Jiang P, Guo Y, Dang R, Yang M, Liao D, Li H, et al. Salvianolic acid B protects against lipopolysaccharide-induced behavioral deficits and 
neuroinflammatory response: involvement of autophagy and NLRP3 inflammasome. J Neuroinflammation. 2017;14(1):239.

361. Feng PP, Fang XS, Zhao SH, Fu JY, Zhang HT, Yi YL, et al. Salvianolic acid B decreases interleukin-1 $\beta$-induced colitis recurrence in mice. Chin Med J (Engl). 2020;133(12):1436-44.

362. Ohsawa I, Ishikawa M, Takahashi K, Watanabe M, Nishimaki K, Yamagata $\mathrm{K}$, et al. Hydrogen acts as a therapeutic antioxidant by selectively reducing cytotoxic oxygen radicals. Nat Med. 2007;13(6):688-94.

363. Ostojic SM. Targeting molecular hydrogen to mitochondria: barriers and gateways. Pharmacol Res. 2015;94:51-3.

364. Shen NY, Bi JB, Zhang JY, Zhang SM, Gu JX, Qu K, et al. Hydrogen-rich water protects against inflammatory bowel disease in mice by inhibiting endoplasmic reticulum stress and promoting heme oxygenase-1 expression. World J Gastroenterol. 2017;23(8):1375-86.

365. Zhang Y, Su W-J, Chen Y, Wu T-Y, Gong H, Shen X-L, et al. Effects of hydrogen-rich water on depressive-like behavior in mice. Sci Rep. 2016;6(1):23742

366. Ooi SL, Green R, Pak SC. N-Acetylcysteine for the Treatment of Psychiatric Disorders: A Review of Current Evidence. Biomed Res Int. 2018;2018:2469486.

367. Sido B, Hack V, Hochlehnert A, Lipps H, Herfarth C, Dröge W. Impairment of intestinal glutathione synthesis in patients with inflammatory bowel disease. Gut. 1998;42(4):485-92.

368. Kimura H, Miura S, Shigematsu T, Ohkubo N, Tsuzuki Y, Kurose I, et al. Increased Nitric Oxide Production and Inducible Nitric Oxide Synthase Activity in Colonic Mucosa of Patients with Active Ulcerative Colitis and Crohn's Disease. Dig Dis Sci. 1997:42(5):1047-54.

369. Menchén LA, Colón AL, Moro MaA, Leza JC, Lizasoain I, Menchén P, et al. $\mathrm{N}$-(3-(Aminomethyl)benzyl)acetamidine, an inducible nitric oxide synthase inhibitor, decreases colonic inflammation induced by trinitrobenzene sulphonic acid in rats. Life Sciences. 2001;69(4):479-91.

370. Choi S-H, Aid S, Bosetti F. The distinct roles of cyclooxygenase-1 and -2 in neuroinflammation: implications for translational research. Trends Pharmacol Sci. 2009;30(4):174-81.

371. Abbasi S-H, Hosseini F, Modabbernia A, Ashrafi M, Akhondzadeh S. Effect of celecoxib add-on treatment on symptoms and serum IL-6 concentrations in patients with major depressive disorder: Randomized double-blind placebo-controlled study. J Affect Disord. 2012;141(2):308-14

372. Müller N, Schwarz MJ, Dehning S, Douhe A, Cerovecki A, Goldstein-Müller $\mathrm{B}$, et al. The cyclooxygenase-2 inhibitor celecoxib has therapeutic effects in major depression: results of a double-blind, randomized, placebo controlled, add-on pilot study to reboxetine. Mol Psychiatry. 2006;11(7):680-4.

\section{Publisher's Note}

Springer Nature remains neutral with regard to jurisdictional claims in published maps and institutional affiliations.

Ready to submit your research? Choose BMC and benefit from:

- fast, convenient online submission

- thorough peer review by experienced researchers in your field

- rapid publication on acceptance

- support for research data, including large and complex data types

- gold Open Access which fosters wider collaboration and increased citations

- maximum visibility for your research: over $100 \mathrm{M}$ website views per year

At BMC, research is always in progress.

Learn more biomedcentral.com/submissions 